\title{
Halogen Bonding in Biomimetic Deiodination of Thyroid Hormones and their Metabolites and Dehalogenation of Halogenated Nucleosides
}

\author{
Santanu Mondal, Debasish Manna, Karuppusamy Raja, and Govindasamy Mugesh*[a]
}

\begin{abstract}
Thyroid hormones (THs) are key players in the endocrine system and play pivotal roles in carbohydrate and fat metabolism, protein synthesis, overall growth, and brain development. The thyroid gland predominantly produces thyroxine or $3,5,3^{\prime}, 5^{\prime}$-tetraiodothyronine (T4) as a prohormone; three isoforms of a mammalian selenoenzyme-iodothyronine deiodinase (DIO1, DIO2 and DIO3)-catalyze the regioselective deiodination of T4 to produce biologically active and inactive metabolites. Whereas DIO1 catalyzes both 5 - and 5'-deiodination of $\mathrm{T} 4, \mathrm{DIO} 2$ and $\mathrm{DIO} 3$ selectively mediate 5 - and 5 -deiodination, respectively. In this review we discuss the regioselective deiodination of $\mathrm{TH}$ in the presence of organochalcogen com-
\end{abstract}

pounds. Naphthalene-based compounds containing sulfur and/or selenium at the peri positions mediate regioselective 5deiodination of THs, detailed mechanistic studies having revealed that the heterolytic cleavage of the $\mathrm{C}-\mathrm{I}$ bond is facilitated by the formation of cooperative Se/S...I halogen bonds and $\mathrm{Se} / \mathrm{S}$...Se chalcogen bonds. We also discuss the biomimetic deiodination of several TH metabolites, including sulfated THs, iodothyronamines, and iodotyrosines. A brief discussion on the dehalogenation of halogenated nucleosides and nucleobases in the presence of organochalcogen compounds is also included.

\section{Introduction}

Thyroid hormones (THs), secreted from the thyroid gland, regulate almost all physiological processes, including protein synthesis, carbohydrate and fat metabolism, neural and brain development, overall growth and maturation of bones, and cardiovascular and renal functions. The production of THs is tightly regulated through the combined action of hypothalamus and pituitary, which secrete thyrotropin-releasing hormone (TRH) and thyroid-stimulating hormone (TSH), respectively, and control TH biosynthesis through a classic negative feedback loop (Figure $1 \mathrm{~A})^{[1]}$ The biosynthesis of THs occurs from a tyrosinerich glycoprotein, thyroglobulin $(\mathrm{Tg})$, located at the follicular lumen of thyroid follicles. The heme-containing enzyme thyroid peroxidase (TPO) catalyzes the iodination of tyrosine residues on $\mathrm{Tg}$ to produce 3-iodotyrosine (MIT) and 3,5-diiodotyrosine (DIT). Phenolic coupling of two DIT residues in the presence of TPO generates Tg-bound 3,5,3',5'-tetraiodothyronine (L-thyroxine or T4), and finally T4 is released from Tg by proteolysis (Figure 1B). Although T4 is the primary product produced by the thyroid gland, a small fraction of the biologically active metabolite 3,5,3'-triiodothyronine (T3) is also generated, through the coupling of DIT and MIT residues on $\mathrm{Tg}^{[1]}$

After its biosynthesis, T4 is released into the bloodstream and is carried to its target organs by three transport proteins: thyroxine-binding globulin (TBG), transthyretin (TTR), and

\footnotetext{
[a] Dr. S. Mondal, Dr. D. Manna, Dr. K. Raja, Prof. Dr. G. Mugesh Department of Inorganic and Physical Chemistry, Indian Institute of Science Bangalore 560012 (India) E-mail:mugesh@iisc.ac.in

(iD The ORCID identification numbers for the authors of this article can be found under https://doi.org/10.1002/cbic.201900619.
}

human serum albumin (HSA). ${ }^{[2]}$ Whereas TBG and TTR each bind two molecules of T4, HSA has four T4-binding sites (Tr14, Figure 1C-E). However, TBG exhibits the highest affinity towards T4 and is a major T4 carrier in blood. T4 is internalized in the target tissues mainly through the action of monocarboxylate transporters 8 (MCT8) and 10 (MCT10) and of organic anion transporter $1 \mathrm{c} 1$ (OATP1C1). ${ }^{[1]}$ In the target tissues, T4 undergoes $5^{\prime}$-deiodination through the action of iodothyronine deiodinase type 1 (DIO1) and type 2 (DIO2) to generate the active metabolite T3. T3 binds to nuclear TH receptors $\alpha$ (TR $\alpha$ ) and $\beta$ (TR $\beta$ ), which recognize the TH-responsive elements (TREs) on target genes and regulate gene expression with the help of co-activator and co-repressor proteins. In this review we discuss the regioselective deiodination of THs in the presence of synthetic deiodinase mimics and the mechanism of $\mathrm{C}_{-}$ I bond activation involving halogen- and chalcogen-bonding interactions. We also discuss the altered reactivity of 5- and 5'iodo substituents in $\mathrm{TH}$ s and several $\mathrm{TH}$ metabolites in the presence of various organochalcogen compounds.

\section{2. lodothyronine Deiodinases (DIOs) and Deiodination of Thyroid Hormones}

DIOs are a family of mammalian selenoenzymes that catalyze the deiodination of THs and play important roles in TH homeostasis. $^{[3]}$ Depending on the primary structure and substrate specificity, three isoforms-iodothyronine deiodinase types 1 (DIO1), 2 (DIO2), and 3 (DIO3)-that exhibit tissue-specific expression patterns are identified. Interestingly, DIOs exhibit different regioselectivity for deiodination: DIO1 catalyzes both 
Santanu Mondal received his Ph.D. from the Indian Institute of Science, Bangalore, in 2016 under the supervision of Prof. G. Mugesh. During his Ph.D. he worked on the biomimetic deiodination of thyroid hormones and metabolites. Currently he is a postdoctoral fellow in the laboratory of Prof. Paul R. Thompson at the University of Massachusetts Medical School, USA.

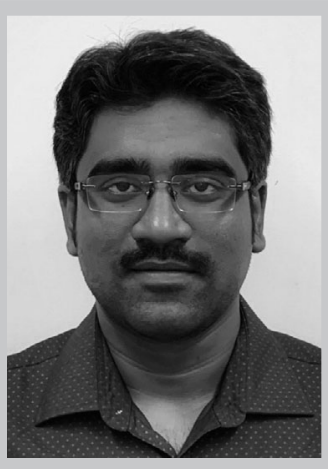

Debasish Manna obtained his Ph.D. from the Indian Institute of Science, Bangalore, in 2013 under the supervision of Prof. G. Mugesh. During his Ph.D. he worked on the regioselective deiodination of thyroid hormones in the presence of organoselenium compounds. After postdoctoral research at the Weizmann Institute of Science, Israel, and at the Broad Institute of Harvard and MIT, USA, he joined the Indian Institute of Science Education and Research, Bhopal, as an Assistant Professor.

Karuppusamy Raja obtained his Ph.D. from the Indian Institute of Science, Bangalore, in 2016 under the supervision of Prof. G. Mugesh. During his Ph.D. he worked on the deiodination of thyroid hormones in the presence of synthetic deiodinase mimics. He is currently a scientist at Syngene International, Ltd. Biocon Park, Bangalore.

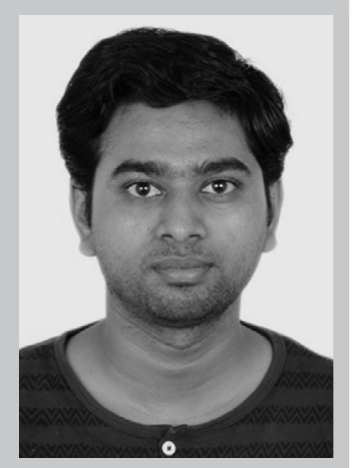

Govindasamy Mugesh received his Ph.D. from the Indian Institute of Technology, Bombay, with Prof. H. B. Singh and carried out postdoctoral research at the Technical University of Braunschweig, Germany, and the Scripps Research Institute, La Jolla, USA. He is currently a Professor at the Indian Institute of Science, Bangalore. His research interests include the development of selenium compounds as functional mimetics of iodothyronine deio-

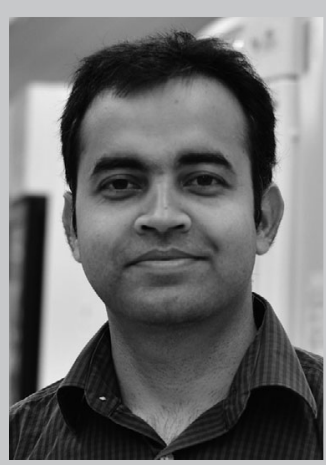

5- and 5'-deiodination of $\mathrm{THs}$, whereas $\mathrm{DIO} 2$ and $\mathrm{DIO} 3$ are completely selective towards $5^{\prime}$ - and 5-deiodination, respectively. DIO1 and DIO2, for example, mediate $5^{\prime}$-deiodination of $\mathrm{T} 4$ to $\mathrm{T} 3$, whereas $\mathrm{DIO} 1$ and $\mathrm{DIO} 3$ catalyze 5 -deiodination of T4 to form the inactive metabolite 3,3',5'-triiodothyronine ( $\mathrm{rT3}$, Figure $2 \mathrm{~A}$ ). Both T3 and rT3 are converted into various other deiodinated metabolites through sequential deiodinations. Each DIO contains an active-site selenocysteine residue, mutation of which to cysteine leads to reduced catalytic efficiency. ${ }^{[3]}$ Furthermore, DIOs exhibit significant sequence similarity in the active-site region, indicating that they share a common mechanism for 5- and 5'-deiodinations.

The crystal structure of the catalytic domain of mouse $\mathrm{DIO} 3$ (mDIO3 ${ }^{\text {cat }}$ ) containing a Sec170Cys mutation was reported by Schweizer et al. ${ }^{[4]}$ The structure indicated that $\mathrm{mDIO}^{\mathrm{cat}}$ exhibits a thioredoxin (Trx) fold consisting of a five-stranded mixed $\beta$ sheet flanked by four $\alpha$-helices (Figure $2 \mathrm{~B}$ ). Whereas the presence of $N$-terminal $\beta$-sheets ( $\beta N 1$ and $\beta N 2)$ and a $3_{10}$-helix $(\Theta 1)$ make $\mathrm{mDIO}^{\text {cat }}$ different from peroxiredoxins, loops $\mathrm{D}, \alpha \mathrm{D}$ and $\beta D$, together termed the DIO-specific insertion, are unique to mDIO3 ${ }^{\text {cat }}$. Catalytically important Sec170 is located in a cleft between $\alpha 1$ and $\beta 1$, corresponding to the position of a peroxidatic cysteine residue in thioredoxin (Figure 2B). The substrate-binding mode, modeled by superimposing the His435...T3...Arg282 clamp of the T3.TR $\beta$ complex on mDio3 ${ }^{\text {cat }} . . . H$ His 202 $\ldots$ Arg275, places the 4 '-OH and 5-iodo moieties near His202 and Sec170, respectively (Figure 2C). The $\beta$-alanine backbone of T4 might be stabilized by Arg275 and Glu259, which were shown to be important for the catalysis. ${ }^{[4]}$

\section{Biomimetic Deiodination of Thyroid Hormones}

Despite several mutagenesis-based investigations and other biochemical studies with DIOs, the mechanism of deiodination remained elusive for decades. The structure of $\mathrm{mDIO}^{\text {cat }}$ suggested that the Sec170 residue abstracts iodine from T4 to form a selenenyl iodide, and that this, upon reaction with the resolving Cys239, generates a Sec170-Cys239 selenosulfide. This intermediate is reduced by Cys168 to regenerate the enzyme active site along with a Cys239-Cys168 disulfide bond, which is further reduced by protein thiols. ${ }^{[3 c, 4]}$ However, the mechanism of $\mathrm{C}-\mathrm{I}$ bond activation and the removal of iodine from THs are poorly understood. Several organochalcogen compounds were developed in efforts to understand the mechanism of $\mathrm{TH}$ deiodination.

Early studies showed that 2,6-diiodo-4-nitrophenol can be monodeiodinated in the presence of selenophenol $(\mathrm{PhSeH})$ under reflux conditions. ${ }^{[5]}$ A T4 derivative-compound 1 (Scheme 1)-underwent both mono- and dideiodination in the presence of sodium hydrogen telluride (NaHTe) to form $\mathbf{2}$ and 3 , respectively, although use of sodium telluride $\left(\mathrm{Na}_{2} \mathrm{Te}\right)$ exclusively generated the dideiodinated product. ${ }^{[6]}$ Sterically hindered selenol 4 was reported to catalyze selective $5^{\prime}$-deiodination of $\mathbf{1}$ in the presence of triethylamine to form $\mathbf{2}$ and the corresponding selenenyl iodide 5 (Scheme 1B). ${ }^{[7]}$ However, higher temperature $\left(50^{\circ} \mathrm{C}\right.$ ) and an organic solvent $\left(\mathrm{CDCl}_{3}\right)$ were 
A)

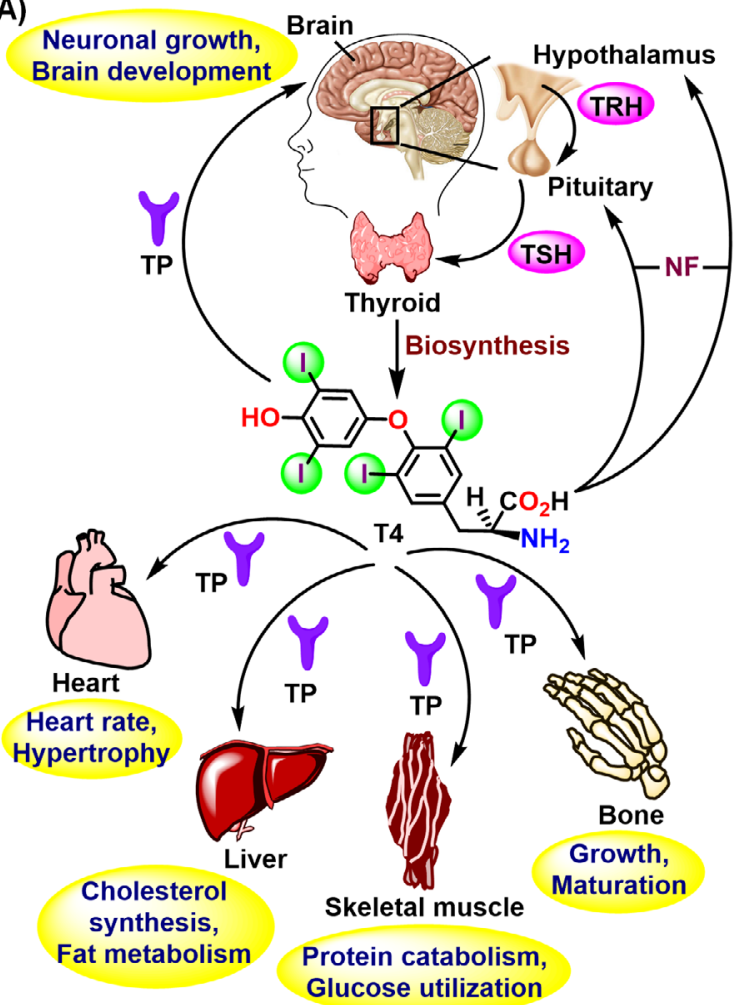

NF: Negative feedback; TP: Transport protein

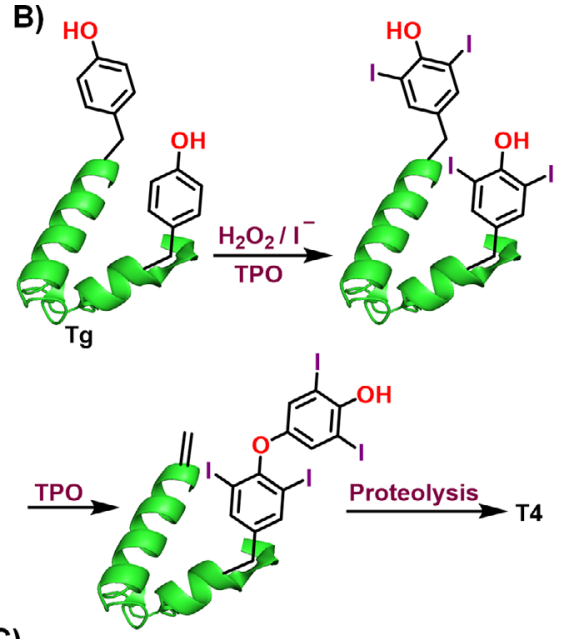

C)

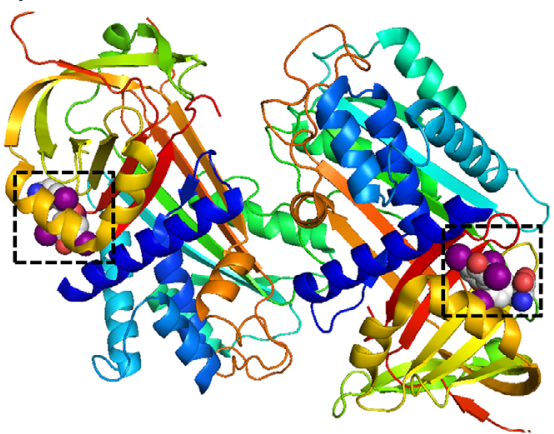

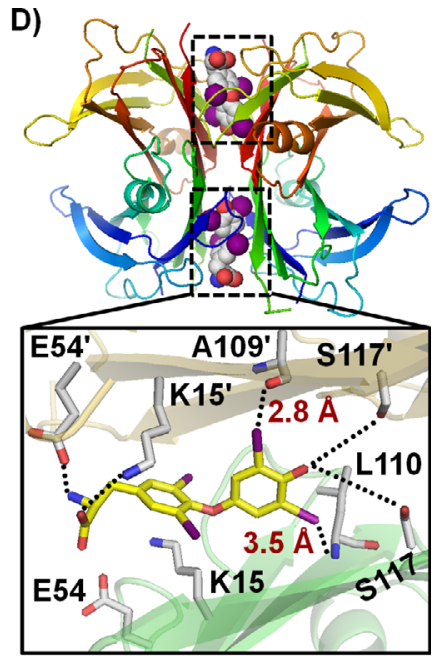

E)

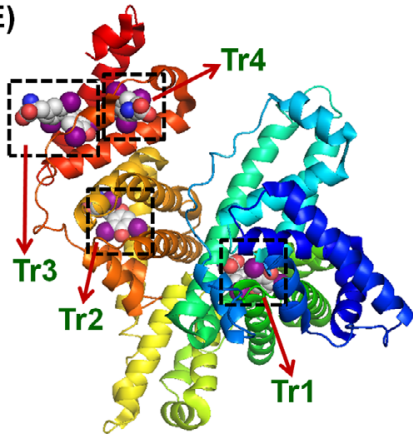

Figure 1. A) Action of THs in different target organs. B) Biosynthesis of T4 from thyroglobulin. Crystal structures of C) TBG·T4 (PDB ID: 2 CEO) ${ }_{1}^{[2]}$ D) TTR·T4 (PDB ID: 2ROX), ${ }^{[2 b]}$ and E) HSA.T4 (PDB ID: 1HK1) ${ }^{[2 a]}$ complexes. T4-binding sites are highlighted by boxes, with T4 shown in space-filled model.

A)

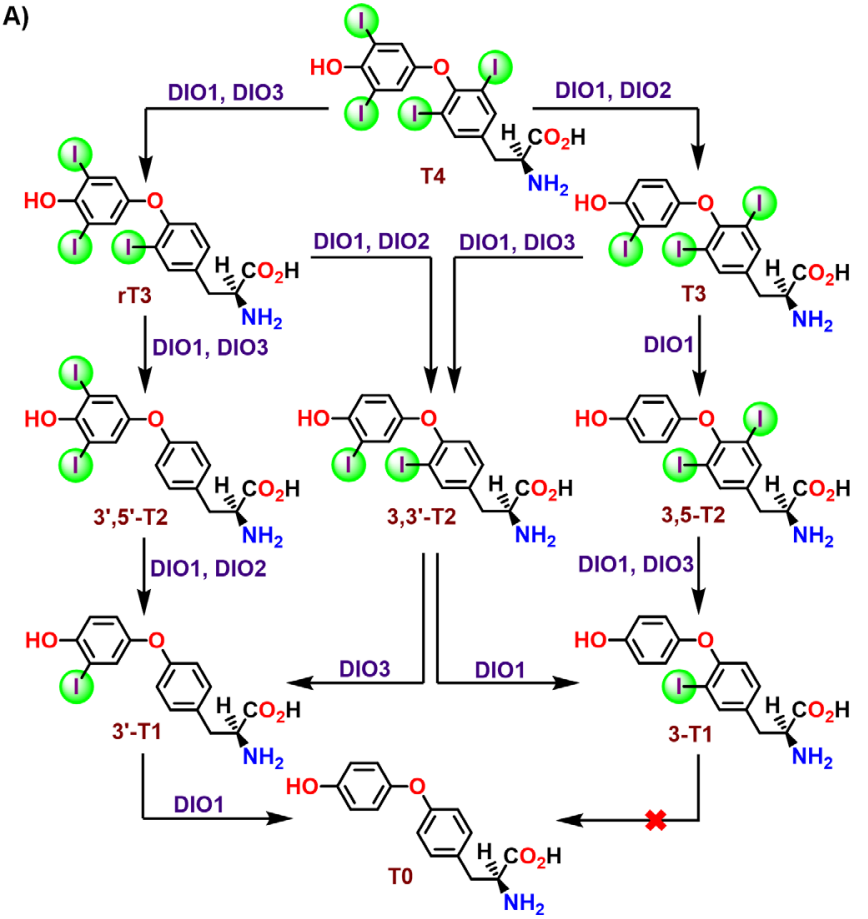

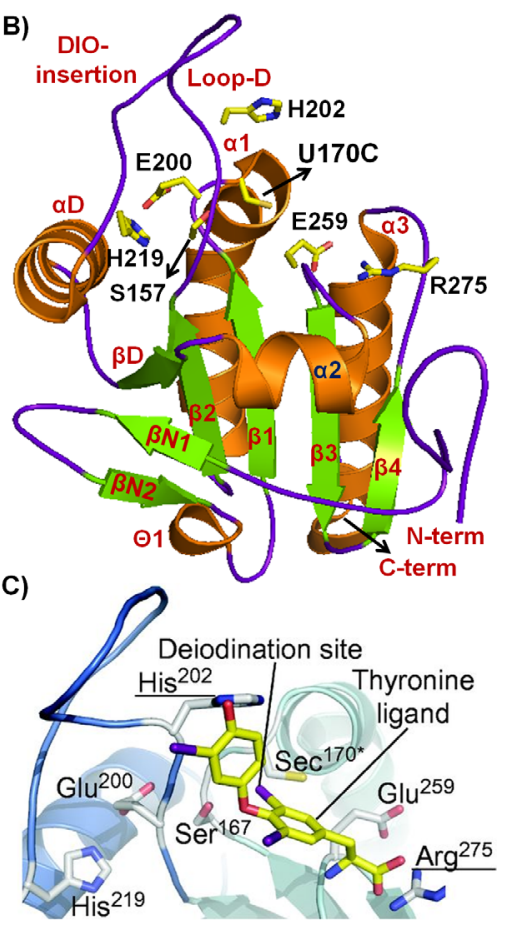

Figure 2. A) Deiodination of THs through the action of DIOs. B) Crystal structure of $\mathrm{mDIO}^{\text {cat }}$, indicating the thioredoxin fold and the amino acid residues important for catalysis (PDB ID: 4TR4). ${ }^{[4]}$ C) T4-binding site on mDIO3 ${ }^{\text {cat }}$. Reproduced, with permission, from ref. [4]. Copyright: 2014, National Academy of Sciences. 
A)

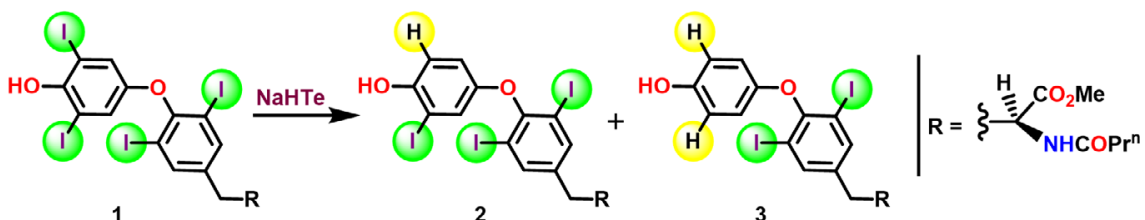

B)<smiles></smiles>

C)

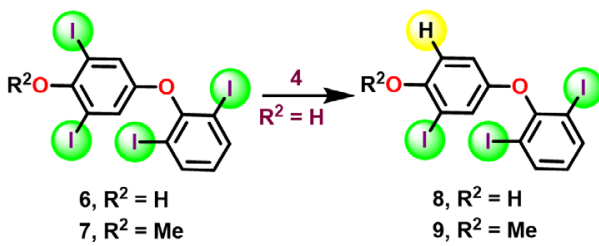

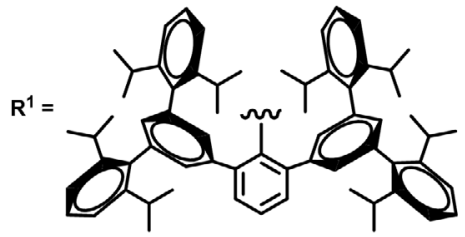

D)

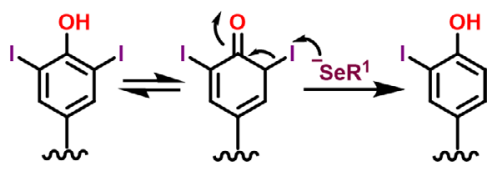

Scheme 1. Deiodination of 1 in the presence of A) NaHTe, and B) 4. C) Deiodination of 6 and 7 in the presence of 4, indicating the importance of the 4'-OH group for $5^{\prime}$-deiodination. D) Proposed mechanism of deiodination. ${ }^{[7]}$

used for this reaction. Interestingly, compound 7, a truncated model of T4 bearing a 4'-methoxy substituent, did not react with 4, whereas compound 6, with a $4^{\prime}-\mathrm{OH}$ group, generated 8 in the presence of 4 (Scheme $1 \mathrm{C}$ ). On the basis of these observations, a mechanism involving the enol-keto tautomerization of the $4^{\prime}-\mathrm{OH}$ group was proposed for $\mathrm{C}-\mathrm{I}$ bond activation of T4 (Scheme 1D). ${ }^{[7]}$
In addition to Sec170, the cysteine residue Cys168, conserved in $\mathrm{DIO} 1$ and $\mathrm{DIO} 3$ (Figure $3 \mathrm{~A}$ ), is important for catalytic activity, because the Cys168Ala DIO3 mutant exhibits half the activity of the wild-type enzyme. ${ }^{[4]}$ This structural motif inspired us to synthesize compound 10 , containing a thiol and a selenol moiety at the peri positions of the naphthalene ring, as a functional DIO model (Figure $3 \mathrm{~B}$ ). ${ }^{[8]}$ Interestingly, treatment
A)

DIO 1: RPLVLNFGSCTUPSF DIO 2: RPLVVNFGSATUPPF DIO 3: RPLVLNFGSCTUPPF

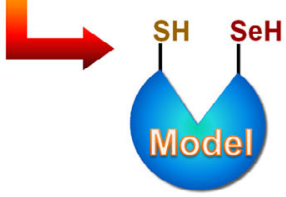

D)

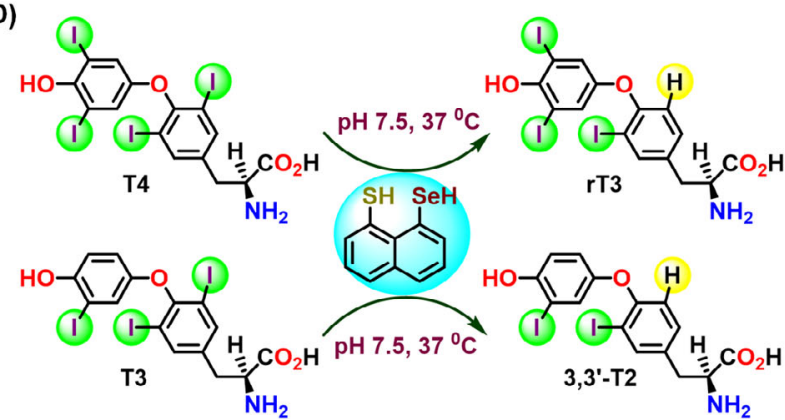

B)

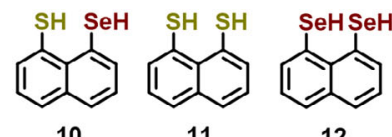

12<smiles>Sc1cccc2cccc([Se]c3ccccc3)c12</smiles>

13<smiles>[SeH]c1cccc2cccc([Se]c3ccccc3)c12</smiles>

14
E)
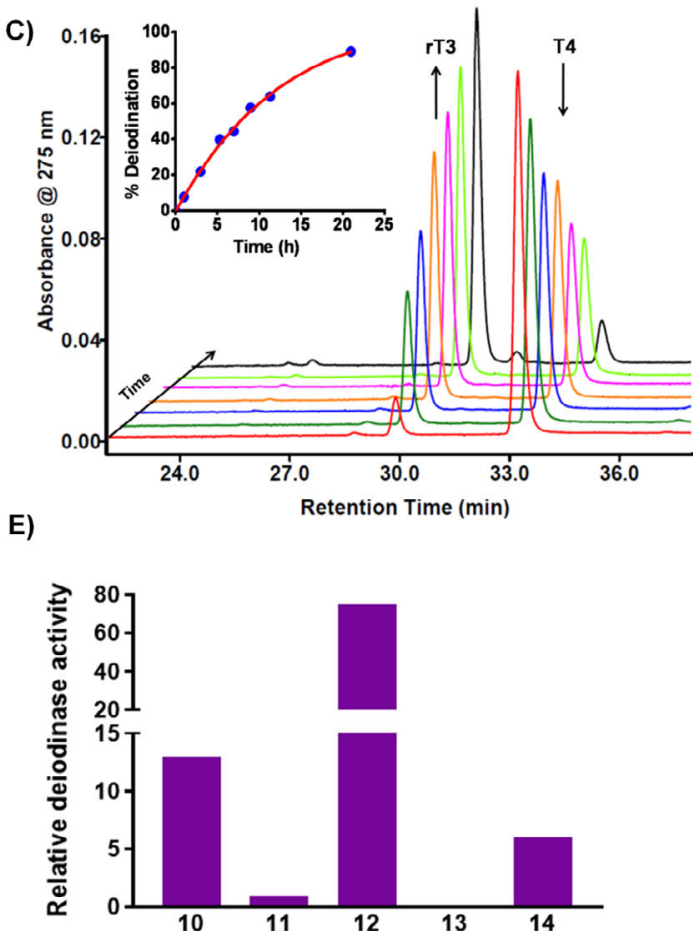

Figure 3. A) Design of a functional DIO model. B) Chemical structures of 10-14. C) HPLC chromatograms for the conversion of T4 to rT3 in the presence of 10 at different time intervals. The inset indicates the time-dependent increase in deiodination. D) Deiodination of T4 and T3 in the presence of 10 to form rT3 and 3,3'-T2, respectively. E) Relative deiodinase activities of 10-14. 
of T4 with 10 under physiologically relevant conditions (phosphate buffer, $\mathrm{pH} 7.5,37^{\circ} \mathrm{C}$ ) led to a time-dependent disappearance of the T4 peak in the HPLC chromatogram with simultaneous appearance of a new peak at around $30 \mathrm{~min}$ (Figure $3 \mathrm{C}$ ). Mass spectrometric analysis and comparison with an authentic sample identified the new product as rT3. Interestingly, no further deiodination was observed even in the presence of excess amounts of 10. Similarly, when T3 was used as a substrate, treatment with 10 led to the formation of 3,3'-T2 (Figure 3D) as the only deiodination product. No deiodination was observed when rT3 and 3,3'-T2 were treated separately with 10 under identical conditions. These results indicate that $\mathbf{1 0}$ mediates exclusive 5-deiodination of T4 and T3, and therefore mimics the activity of DIO3. Notably, 10 was oxidized to the corresponding selenosulfide during the deiodination, so dithiothreitol (DTT) was used to maintain a reducing environment in the assay. However, DTT neither altered the regioselectivity nor enhanced the rate of deiodination. ${ }^{[8]}$

Interestingly, replacement of the selenol moiety in 10 with a thiol group (compound 11) led to an almost 13-fold decrease in the activity (Figure $3 \mathrm{E}$ ) ${ }^{[8]}$ consistently with the lower activity of the Sec170Cys mutant in relation to wild-type $\mathrm{DIO} .^{[3]}$ In contrast, the replacement of the thiol group in 10 with another selenol moiety (compound 12) led to an almost sixfold enhancement in the activity (Figure $3 \mathrm{E}$ ), thus indicating that the Cys $168 \mathrm{Sec}$ mutation in DIO3 would likely increase the catalytic efficiency. ${ }^{[9]}$ Notably, despite having higher activity, 12 neither showed alteration of the regioselectivity of deiodination nor mediated further deiodination of $\mathrm{rT3}$ and 3,3'-T2. Interestingly, compound 14, with a SePh substitution, exhibited activity almost 12 times weaker than that of $\mathbf{1 2}$, whereas 13 was inactive, thus indicating that the presence of selenium in the selenol form is crucial for efficient deiodination (Figure $3 \mathrm{E}$ ). ${ }^{[9]}$

The activities of $\mathrm{DIO} 1$ and $\mathrm{DIO} 3$ are known to be $\mathrm{pH}$-dependent. ${ }^{[\mathrm{b}]}$ Whereas, at neutral $\mathrm{pH}, \mathrm{DIO} 1$ catalyzes $5^{\prime}$-deiodination of $\mathrm{T} 4$, at alkaline $\mathrm{pH}$ it mediates 5-deiodination of T3. In contrast, $\mathrm{DIO} 3$ does not catalyze $5^{\prime}$-deiodination of $\mathrm{T} 4, \mathrm{~T} 3$, or rT3 over a wide $\mathrm{pH}$ range, although it exhibits significantly higher activity at alkaline $\mathrm{pH}$. We studied the deiodination of T4 and T3 in the presence of 10 and 12 at various $\mathrm{pH}$ values. Both 10 and 12 mediated only 5-deiodination of these hormones over a wide $\mathrm{pH}$ range. Furthermore, these compounds exhibited significantly higher deiodinase activity at alkaline $\mathrm{pH}^{\left[{ }^{[9]}\right.}$

DIO1 activity is sensitive to gold thioglucose (GTG), iodoacetic acid (IAA), and the anti-hyperthyroid drug 6-n-propyl-2-thiouracil (PTU). However, DIO2 and DIO3 are insensitive to these inhibitors. ${ }^{[3 a, b, 10]}$ Whereas GTG and IAA inactivate DIO1 by covalently modifying the Sec170 residue, PTU reacts with the selenenyl iodide intermediate, formed during the enzymatic reaction, to generate a dead-end selenosulfide product. Deiodination of $\mathbf{1}$ in the presence of $\mathbf{4}$ (Scheme 1) also proceeded via the selenenyl iodide $5 .^{[7]}$ To investigate whether the 5 -deiodination of $\mathrm{T} 4$ in the presence of $\mathbf{1 2}$ proceeds through such an intermediate, we studied this reaction in the presence of PTU. However, no inhibition of activity was observed up to $0.45 \mathrm{~mm}$ PTU, thus indicating that the deiodination of T4 in the pres- ence of 12 might not generate a selenenyl iodide. ${ }^{[11]}$ Interestingly, treatment of $\mathbf{1 2}$ with IAA did not generate the expected Se-carboxymethylated product, but instead led to the rapid deiodination (even faster than that of T4 and T3) of IAA to acetic acid. These observations suggest that $\mathrm{DIO} 3$ might deiodinate IAA and, therefore, is insensitive to IAA..$^{[9,11]}$

Although the $5^{\prime}$-deiodination of T4 in the presence either of DIO1 or of synthetic selenols was shown to involve keto-enol tautomerism of the 4'-OH group (Scheme 1D), such a mechanism is not feasible in the case of 5-deiodination. Therefore, it was hypothesized that the deiodination of T4 in the presence of 10 might follow a nucleophilic aromatic substitution $\left(\mathrm{S}_{N} \mathrm{Ar}\right)$ pathway. ${ }^{[11]}$ The attack of 10 at the 3-position of T4, leading to the formation of 15 through the Meisenheimer complex (Figure $4 \mathrm{~A}$ ), and subsequent attack of the thiol on the electrophilic selenium atom of $\mathbf{1 5}$ might generate rT3. However, no formation of any species such as 15 , containing a carbon-selenium bond, was observed by ${ }^{77}$ Se NMR spectroscopy, even at low temperature $\left(-20^{\circ} \mathrm{C}\right)$. At $-20^{\circ} \mathrm{C}$, deiodination of $\mathrm{T} 4$ did indeed produce $\mathrm{rT3}$ and the oxidized selenosulfide corresponding to 10, thus indicating that the reaction does not generate any stable intermediates. ${ }^{[11]}$ Accordingly, it was hypothesized that the $\mathrm{C}-\mathrm{I}$ bond in $\mathrm{T} 4 \mathrm{might}$ be activated through the formation of a halogen bond (XB) between the thiol/selenol system in 10,11 , or 12 and iodine. Owing to the anisotropic charge distribution, halogen atoms in organic halides contain significant amounts of positive charge ( $\sigma$-hole) along the $C-X$ axis and form XBs in the presence of electron donors. ${ }^{[12]}$ The $5^{\prime}$-iodo substituents of T4 enter into $1 . . . \mathrm{O}$ and I...N XBs with the Ala109 and Leu110 residues, respectively, of TTR (Figure $1 \mathrm{D}) .{ }^{[2 \mathrm{~b}]}$ With the aid of density functional theory (DFT), Bayse and Rafferty showed that S...I and Se...I interactions can activate $\mathrm{C}-\mathrm{I}$ bonds in aromatic iodides, and the activation barriers for such reactions in the cases of $\mathrm{MeSeH}$ and $\mathrm{MeSH}$ were calculated to be 17.6 and $19.8 \mathrm{kcal} \mathrm{mol}^{-1}$, respectively. Furthermore, the deprotonation of $\mathrm{MeSeH}$ to $\mathrm{MeSe}^{-}$was shown to strengthen the Se...I interaction. ${ }^{[13]}$

To investigate the possibility of formation of XBs by THs in the presence of selenols/thiols, we generated electrostatic potential maps of THs. Interestingly, the iodine atoms in the THs contain significant amounts of positive charge for possible formation of XBs (Figure 4B). ${ }^{[11]}$ Furthermore, treatment of 16 (Figure $4 C$ ), which lacks the additional thiol/selenol group and does not catalyze deiodination of $\mathrm{T} 4 / \mathrm{T} 3$, with increasing concentrations of iodobenzene (IB) resulted in a gradual downfield shift of the ${ }^{77}$ Se signal of 16 , indicating the formation of a Se...1 $X B$ (Figure 4D). To understand the strength of such XBs formed by 10-12, we performed DFT calculations on complexes 17-22 with IB as a model system (Figure 4C). Briefly, the replacement of the thiolate system in $\mathbf{1 7}$ with a selenolate system, as in compound 18, marginally increases $\left(\approx 1.7 \mathrm{kcal} \mathrm{mol}^{-1}\right)$ the $\mathrm{XB}$ strength. However, the presence of an additional selenolate or thiolate at the peri position, as in compounds 19-22, dramatically enhances the $X B$ strength and decreases the $C-I$ bond order in comparison with those in 17 and 18 (Figure $4 C$; see table). Notably, in the cases of 19-22, in addition to the E...I $X B, S e / S \cdots E$ interactions (chalcogen bonding) are also observed. 
A)

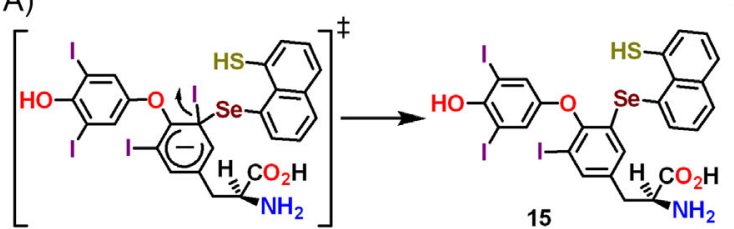

B)

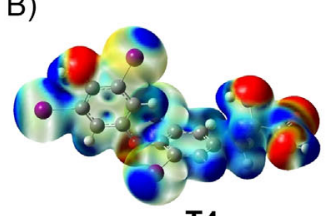

T4
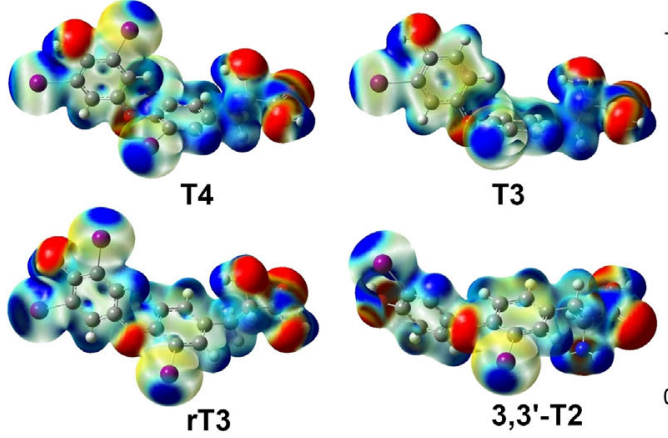

T3

E)

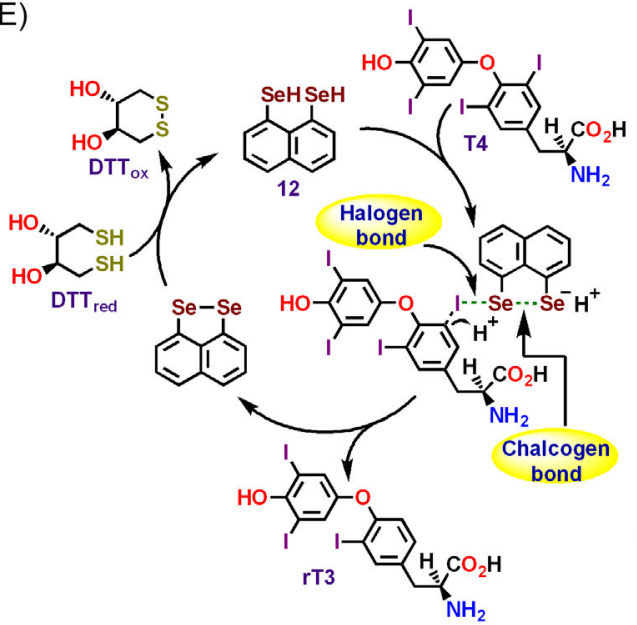

C)<smiles>Oc1cccc2ccccc12</smiles>

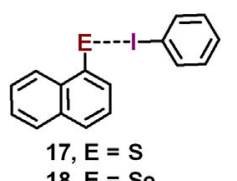
$18, \mathrm{E}=\mathrm{Se}$

D)

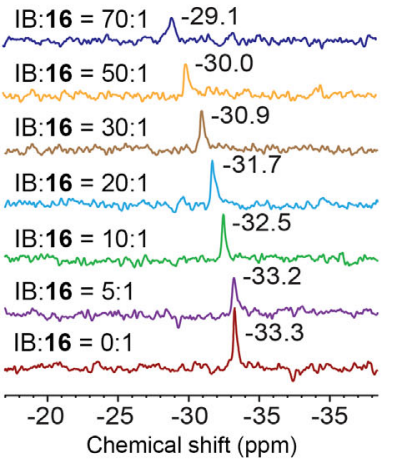

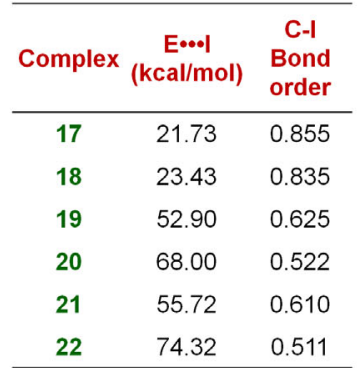

F)

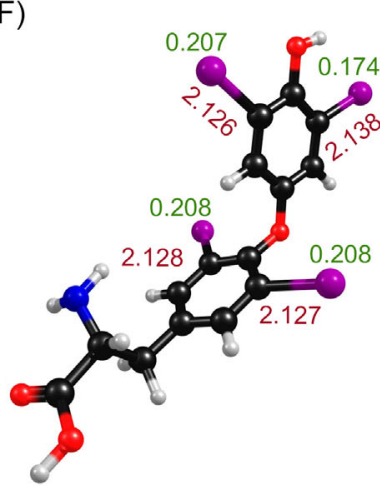

H)
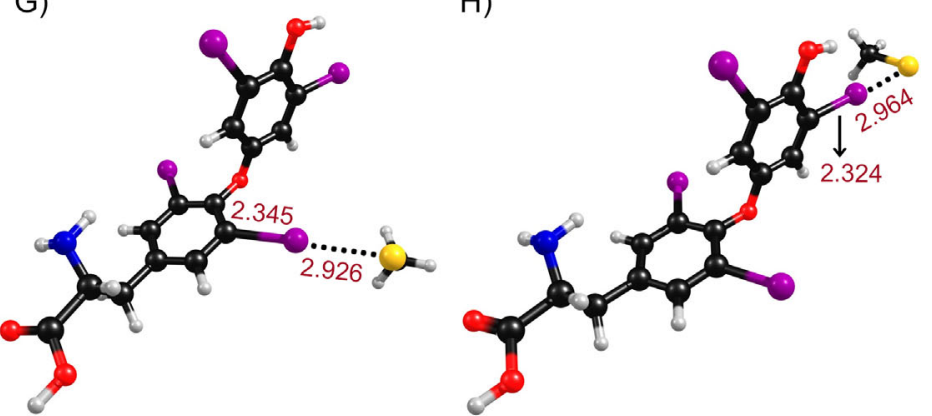

Figure 4. A) Possible $\mathrm{S}_{\mathrm{N}} \mathrm{Ar}$ mechanism for deiodination of T4. B) Electrostatic potential maps of THs. Reproduced, with permission, from ref. [11]. Copyright: 2011, American Chemical Society. C) Chemical structures of 16-22. The table lists the E...I interaction energies and C-I bond orders in 17-22. D) Downfield shift of the ${ }^{77}$ Se NMR signal of 16 upon addition of iodobenzene (IB), indicating the formation of a Se...I XB. E) Proposed mechanism of deiodination of T4. F) Optimized structure of T4 indicating the charges (green) on iodo substituents and C-I bond lengths (brown). G), H) Optimized structures of halogenbonded complexes formed through $\mathrm{G}$ ) the 5-, and H) the 5'-iodo substituents of T4 with methyl selenolate ( $\left.\mathrm{MeS}^{-}\right)$. $\mathrm{C}-\mathrm{I}$ and Se-... bond lengths are given in $\AA$.

These observations indicate that upon donation of electron density to the $\sigma^{*}$ orbital of the $C-I$ bond, the chalcogen center, involved in $\mathrm{XB}$, increases in electrophilicity and enters into a Se/S...E chalcogen-bonding interaction. On the basis of these observations, we proposed a mechanism of deiodination of T4 in the presence of 12 (Figure $4 \mathrm{E}$ ). ${ }^{[11]}$ Initial formation of a Se...I XB between T4 and $\mathbf{1 2}$ generates a partial positive charge on the halogen-bonded selenium atom and facilitates Se...Se chalcogen bonding. This further strengthens the Se...1 interaction, leading to a heterolytic cleavage of the $\mathrm{C}-\mathrm{I}$ bond. Protonation of the resulting carbanion produces $\mathrm{rT3}$ and $\mathrm{HI}$, and $\mathbf{1 2}$ is oxidized to a diselenide that is subsequently reduced by DTT. Although 22, containing a thiolate/selenolate pair, forms a stronger XB with IB than 20, which contain two selenolate groups (Figure $4 C$; see table), the higher activity of 12 in relation to 10 is explained on the basis of complete and par- tial deprotonation of selenol and thiol groups, respectively, at physiological pH. Notably, 10 and 12 exhibited similar activity at $\mathrm{pH}$ 11. Natural bond orbital (NBO) analysis indicated that the 5 -iodo substituents in T4 contain more positive charge than their $5^{\prime}$-iodo counterparts (Figure 4F). ${ }^{[14]}$ Consequently, a 5iodo substituent $\left(66.23 \mathrm{kcal} \mathrm{mol}^{-1}\right)$ enters into a stronger Se...I interaction with $\mathrm{MeSe}^{-}$than a $5^{\prime}$-iodo substituent $(58.07 \mathrm{kcal}$ $\mathrm{mol}^{-1}$, Figure $4 \mathrm{G}, \mathrm{H}$ ), thus accounting for the observed regioselectivity of deiodination of T4 in the presence of 10-12. Although the neighboring thiol/selenol moieties in compounds 10-12 are responsible for the formation of $\mathrm{S} / \mathrm{Se} . . \mathrm{S} / \mathrm{Se}$ chalcogen bonding that enhances the strength of $\mathrm{S} / \mathrm{Se} \ldots \mathrm{.}$ halogen bonding and helps in the reductive cleavage of the $\mathrm{C}-\mathrm{I}$ bonds in THs in the presence of deiodinase mimics, no such type of cooperative mechanism is known for the DIOs. Notably, the Cys 168 and Cys239 residues in DIO3 help in reducing the sele- 
nenyl iodide intermediate and regenerating the enzyme active site (discussed earlier).

Sicilia and co-workers studied the transition states (TSs) of the regioselective 5-deiodination of T4 in the presence of 1012 with the aid of solution-state DFT calculations. ${ }^{[15]}$ Inspired by the histidine residue in the DIO active site (vide infra), imidazole was used as a general acid/base for the deiodination. The calculated free energy profile revealed that the deiodination reaction follows four steps (Figure 5). In the first step, a selenolate/thiolate is generated by proton abstraction from one of the selenols/thiols in 10-12 by imidazole. Next, the formation of a $\mathrm{Se} / \mathrm{S}$...I XB elongates the $\mathrm{C}-\mathrm{I}$ bond; proton transfer from the imidazolium ion to the carbon atom of the $\mathrm{C}-\mathrm{I}$ bond then leads to the heterolytic cleavage of this bond along with the formation of a selenenyl/sulfenyl iodide intermediate (INT2). Subsequently, the chalcogen interaction facilitates proton transfer from the adjacent selenol/thiol to iodine, leading to the formation of a chalcogen-chalcogen bond and elimination of $\mathrm{HI}$. The rate-determining step of this whole process is the heterolytic cleavage of the $\mathrm{C}-\mathrm{I}$ bond: that is, the formation of INT2 from INT1 by way of TS2 (Figure 5 B). The activation
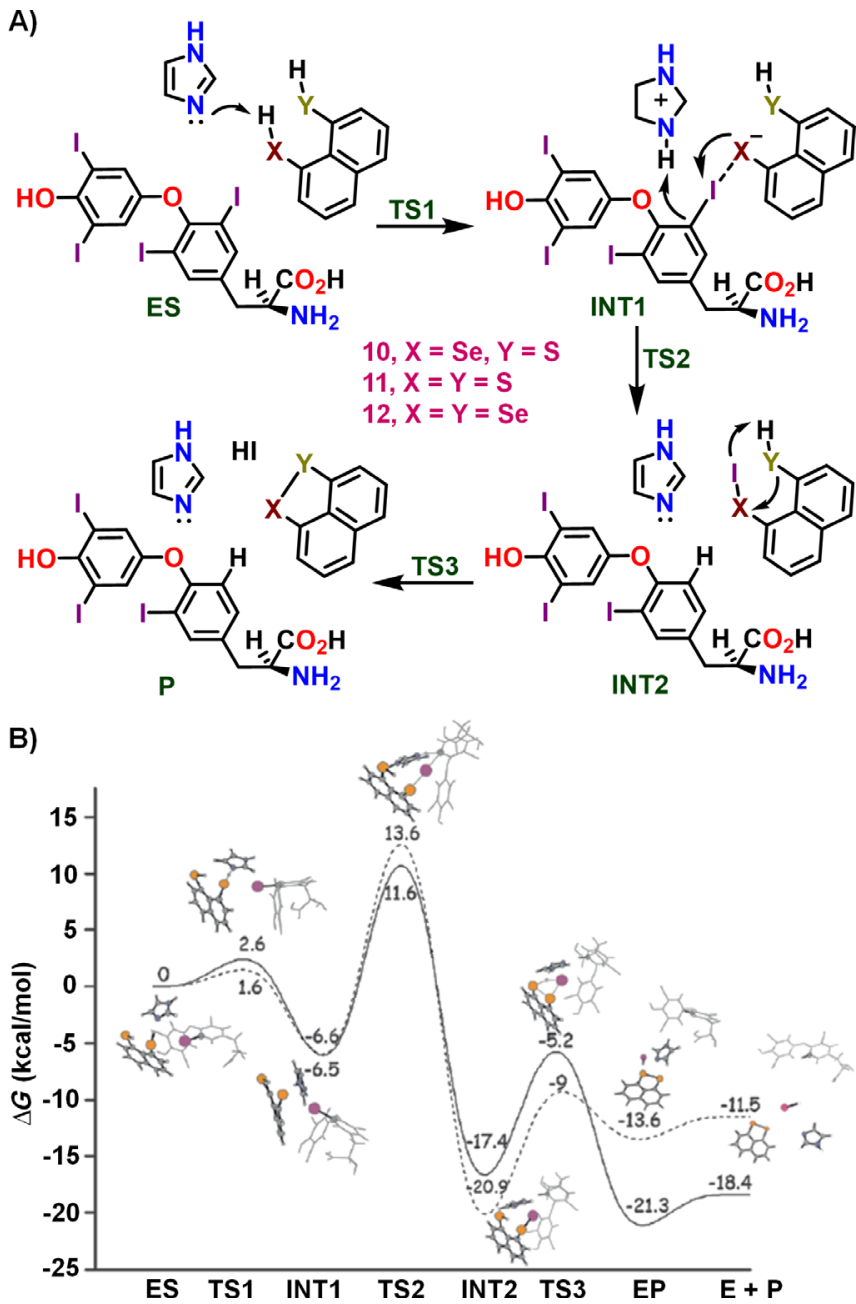

Figure 5. A) Proposed steps, and B) free energy profile of the deiodination of T4 in the presence of $\mathbf{1 0}(\ldots)$ and $12(-)$. Panel $B$ is reproduced, with permission, from ref. [15]. Copyright: 2015, Wiley-VCH. ${ }^{[15]}$ energy barriers for this step are 18.2, 20.1, and $22.7 \mathrm{kcal} \mathrm{mol}^{-1}$ in the cases of 12,10 , and 11 , respectively. ${ }^{[15]}$ These results are consistent with the observed reactivity of 10-12 in the deiodination of T4. Although these TS calculations also suggest the pivotal role of $\mathrm{XBs}$ and of chalcogen bonding in the deiodination, the formation of selenenyl/sulfenyl iodide intermediates was not detected experimentally (vide supra). ${ }^{[1]}$

The use of site-directed mutagenesis, $\mathrm{pH}$-dependent kinetics, and histidine-targeted reagents suggested that, in addition to $\mathrm{Cys}$ and $\mathrm{Sec}$, one or more histidine residues are important for the activity of DIOs. ${ }^{[3]}$ The formation of a selenolate/imidazolium zwitterion is known to activate Sec170 of DIO1 for nucleophilic attack. Although His158 and His174 are conserved in $\mathrm{DIO} 2$ and $\mathrm{DIO} 3$, selenolate/imidazolium zwitterion formation is unknown for these enzymes. To understand the role of histidine in deiodination, we synthesized 23-29, containing basic secondary amino groups (Figure 6A). ${ }^{[8,9,11]}$ Interestingly, 23 and 26-29 showed significantly higher activities than the parent compounds 11 and 12, respectively, whereas 24 and 25 exhibited lower activities than 10 (Figure 6B). Detailed theoretical and NMR spectroscopic studies indicated that the presence of the amino group facilitates Se... N chalcogen bonding in these compounds and leads to deprotonation of the nearby thiol/ selenol. As an example, the ${ }^{77}$ Se signal for one of the selenols (76 ppm) in $\mathbf{2 6}$ is significantly shifted upfield in relation to the other selenol (214 ppm) in the same compound and to that in 12 (155 ppm), thus indicating the deprotonation of the selenol

A)

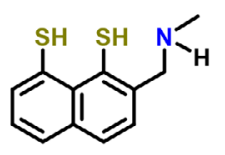

23

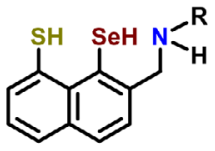

24, $R=M e$ $25, \mathrm{R}=\mathrm{Et}$

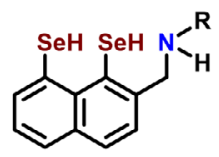

26, $\mathrm{R}=\mathrm{Me} ; 27, \mathrm{R}=\mathrm{Et}$ 28, $\mathbf{R}=\mathrm{Pr} ; 29, \mathbf{R}=i \mathrm{Pr}$
B)

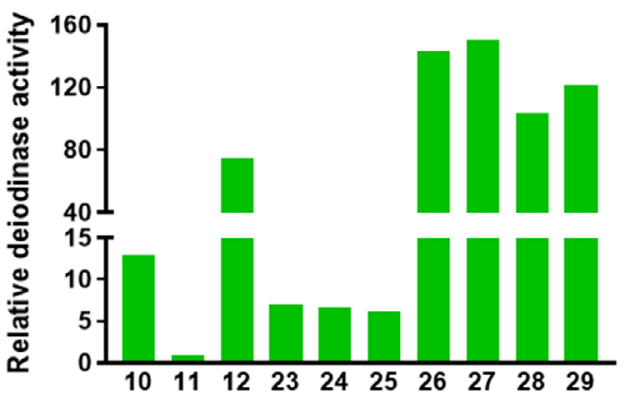

C)

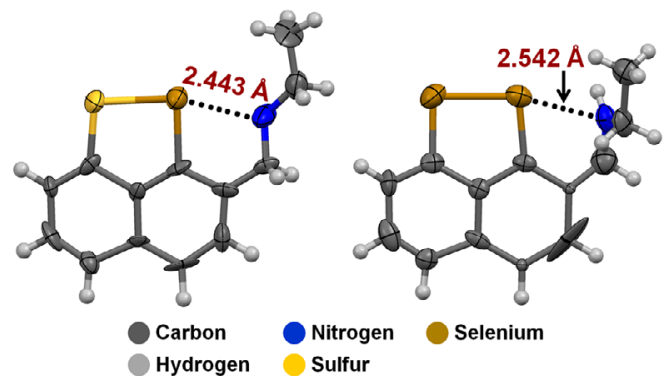

Figure 6. A) Chemical structures, and B) relative deiodinase activities of 2329. C) Crystal structures of the corresponding selenosulfide and diselenide of $\mathbf{2 5}$ and $\mathbf{2 7}$, indicating the Se... $\mathrm{N}$ interactions. 
next to the amino group. Se... $\mathrm{N}$ interactions are also observed in the crystal structures of the oxidized selenosulfide and diselenide forms of these compounds (Figure $6 \mathrm{C}$ ). The higher activities of 23 and 26-29 in relation to the parent compounds are explained on the basis of Se... $\mathrm{N}$ interactions and selenol deprotonation, strengthening both Se...Se and Se...I interactions at the intermediate stage and facilitating the $\mathrm{C}-\mathrm{I}$ bond cleavage. Compounds $\mathbf{2 4}$ and $\mathbf{2 5}$ would be expected to form XBs with T4 through their selenium centers, so the presence of the amino group near the selenol sterically hinders such interaction and these compounds therefore exhibit lower activity than $10 .^{[11]}$

Despite their higher activities, 23-29 mediate only 5-deiodination of T4 and T3. Interestingly, replacement of selenium in 10 and 12 with tellurium, which would be expected to form stronger XBs than selenium, led to both 5- and $5^{\prime}$-deiodination of T4. ${ }^{[16]}$ Treatment of T4 with catalytic amounts of $\mathbf{3 0}$ and $\mathbf{3 1}$ (Figure 7A) produced only rT3, whereas the use of stoichiometric amount of these compounds generated six deiodinated products- $\mathrm{rT} 3,3,3^{\prime}-\mathrm{T} 2,3^{\prime}, 5^{\prime}-\mathrm{T} 2,3-\mathrm{T} 1,3^{\prime}-\mathrm{T} 1$, and T0-from T4 (Figure 7B). In terms of the concentrations required for 5-deiodination of T4, $\mathbf{3 0}$ and $\mathbf{3 1}$ were found to be over 1000 times more active than 12. Interestingly, in contrast to 10 and $\mathbf{1 2}$, compound 30, containing a thiol/tellurol pair, exhibited higher activity than $\mathbf{3 1}$, containing two tellurol groups (Figure 7C). TS calculations similar to those described earlier for 10-12 indicated that the activation energy barrier for the rate-determining step is slightly higher for $\mathbf{3 1}$ than $\mathbf{3 0}$ and the same for $\mathbf{1 2}$ is higher than those for both 30 and $31 .{ }^{[17]}$ These computational results are totally in agreement with the observed reactivity of 12, 30, and 31 in the deiodination of T4. Furthermore, independent treatment of deiodinated T4 metabolites indicated that $\mathbf{3 0}$ and $\mathbf{3 1}$ mediate all the possible 5- and 5'-deiodina-

A)<smiles>[Hg]c1cccc2c([Hg])cccc12</smiles>

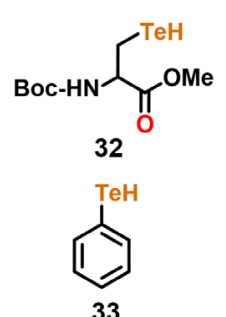

C)
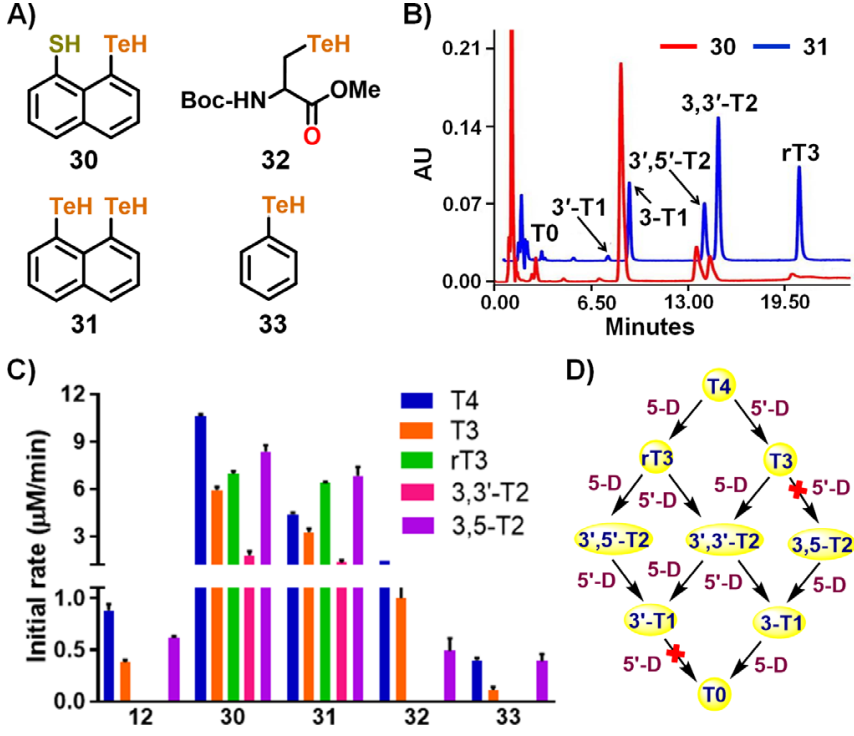

D)

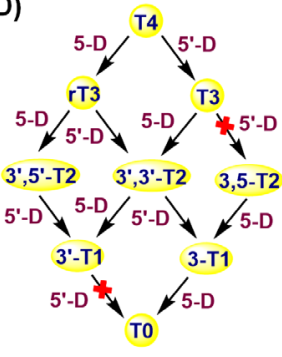

Figure 7. A) Chemical structures of 30-33. B) HPLC chromatograms showing deiodination of T4 in the presence either of $\mathbf{3 0}$ or of 31. C) Comparison of deiodination activities of $\mathbf{1 2}$ and 30-33 for different THs. D) Sequential deiodination of T4 to T0 in the presence either of $\mathbf{3 0}$ or of $\mathbf{3 1}$. D refers to deiodination. tions, except for the $5^{\prime}$-deiodinations of T3 and $3^{\prime}-\mathrm{T} 1$ to form 3,5-T2 and T0, respectively (Figure 7C and D). Interestingly, 32 and 33, each containing one tellurol moiety, also mediate 5-deiodination of T4, T3, and 3,5-T2 but with significantly lower initial rates than $\mathbf{3 0}$ and 31 (Figure 7C). ${ }^{[16]}$ Notably, selenocysteine and selenophenol (PhSeH) do not exhibit such activity.

Although the tellurium-containing compounds mediate 5'deiodination of $\mathrm{TH}, \mathrm{DIO} 1$ and $\mathrm{DIO} 2$ mediate the same through having selenocysteine in the active site, thus indicating that some other factor might alter the reactivity of the 5- and 5'iodo substituents. Recently we have shown that commercially obtained T4 exists in at least two different stable conformations with different physical properties. ${ }^{[18]}$ Furthermore, solidstate ${ }^{13} \mathrm{C}$ NMR indicated that the reactivities of the $\mathrm{C}-\mathrm{I}$ bonds in these two conformations are different. Therefore, we hypothesized that the reactivities of the 5- and 5'-iodo substituents of T4 might be altered by different conformational parameters. Notably, we found that T4 binds to its transport proteins and receptors in various conformations (Figure $8 \mathrm{~A}$ ). In most of the conformations the 5 -iodo substituent enters into a stronger XB with $\mathrm{MeSe}^{-}$than its $5^{\prime}$-iodo counterpart, but at $\Phi=0^{\circ}$ and $\Phi^{\prime}=94^{\circ}$ both of these iodo substituents form equally strong XBs with $\mathrm{MeSe}^{-}$, thus indicating that both 5- and 5'-deiodinations would be equally feasible in this conformation (Figure $8 \mathrm{~B}$ ). Furthermore, variations in $\chi^{1}$ and $\psi$ at $\Phi=0^{\circ}$ afforded many conformations of $\mathrm{T} 4$ in which the $5^{\prime}$-iodo substituent forms a stronger $\mathrm{XB}$ than its 5 -iodo counterpart (Figure $8 \mathrm{C}$ ). ${ }^{[18]}$ These observations suggest that DIOs might bind T4 in different conformations to catalyze regioselective 5- and 5'-deiodinations.

\section{Biomimetic Deiodination of Thyroid Hormone Metabolites}

In addition to deiodination, THs undergo a variety of other metabolic pathways, including sulfation, glucuronidation, decarboxylation, and oxidative deamination. ${ }^{[1 a]}$ These pathways mainly increase the excretion of THs through urine and/or bile. Interestingly, like THs, these metabolites are further deiodinated through the action of DIOs. T4S, containing a sulfate conjugation on the 4'-OH group, for example, undergoes 5-deiodination in the presence of DIO1 (Figure 9A). Similarly, T3S and rT3S undergo $5^{\prime}$ - and 5-deiodination, respectively, by DIO1 to form 3,3'-T2S. However, DIO1 does not catalyze 5'-deiodination of T4S to T3S, and none of these metabolites is accepted by DIO2 and DIO3 as a substrate. ${ }^{[1 \mathrm{a}, 19]}$

We studied the biomimetic deiodination of sulfated THs in the presence of 10, 12, 26, and 34-37 (Figure 9B). In contrast to $T 4$, deiodination of T4S in the presence of 12 produces T3S, rT3S, and 3,3'-T2S, thus indicating that the sulfate conjugation alters the regioselectivity of deiodination (Figure 9C). ${ }^{[20]}$ Furthermore, T3S and rT3S undergo $5^{\prime}$ - and 5-deiodination, respectively, in the presence of 12 to form 3,3'-T2S. However, $3,3^{\prime}-\mathrm{T} 2 \mathrm{~S}$ does not undergo further deiodination in the presence of 12. Comparisons of initial rates indicate that the deiodination of T4S in the presence of $\mathbf{1 0}, \mathbf{1 2}, \mathbf{2 6}$, and $\mathbf{3 4 - 3 7}$ is faster than that of T4 by factors of almost three to eight (Figure 9D). 
A)

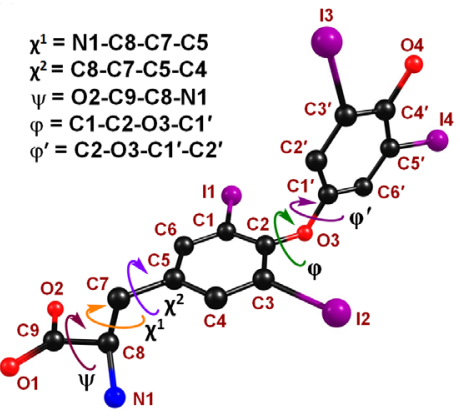

B)

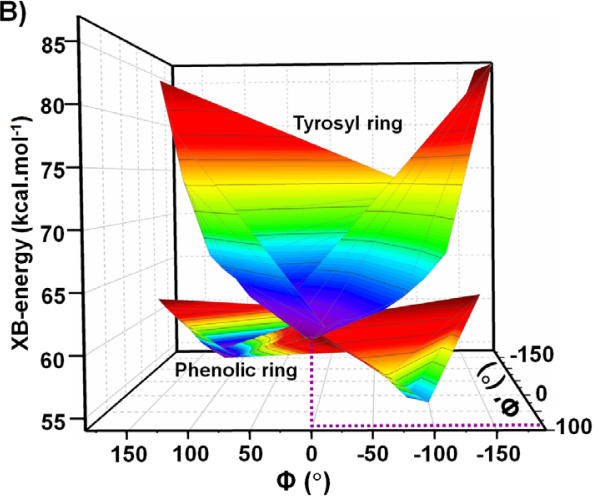

\begin{tabular}{ccccccc}
\hline \multirow{2}{*}{$\left.{ }^{\circ}\right)$} & $\begin{array}{c}\text { T4 } \\
\text { (Form I) }\end{array}$ & $\begin{array}{c}\text { T4 } \\
\text { (Form II) }\end{array}$ & $\begin{array}{c}\text { TBG } \\
\text { •T4 }\end{array}$ & $\begin{array}{c}\text { TTR } \\
\text { •T4 }\end{array}$ & $\begin{array}{c}\text { HSA } \\
\text { •T4 }\end{array}$ & $\begin{array}{c}\text { TR } \beta \\
\text { •T4 }\end{array}$ \\
\hline \multirow{2}{*}{$\chi^{1}$} & -158.6 & -68.0 & 73.2 & -166.3 & 142.6 & -43.1 \\
& 64.0 & 68.8 & 72.1 & -105.8 & -102.1 & -43.1 \\
$\chi^{2}$ & -97.1 & -84.8 & 83.2 & -91.3 & 67.5 & -50.6 \\
& -92.1 & -85.8 & 84.0 & -104.1 & -66.3 & \\
& 133.6 & 178.2 & 175.1 & -98.8 & 125.5 & \\
$\psi$ & 169.2 & 176.2 & 174.7 & 112.4 & 126.5 & -171.7 \\
& 79.7 & 74.4 & 99.2 & 13.6 & 86.1 & \\
$\varphi$ & 109.1 & 109.3 & 100.1 & 59.3 & 102.5 & 80.6 \\
& 37.4 & 35.8 & -21.6 & 60.9 & 32.8 & \\
$\varphi^{\prime}$ & 35.5 & -41.7 & -21.6 & 5.6 & -19.7 & 23.1 \\
\end{tabular}

C)

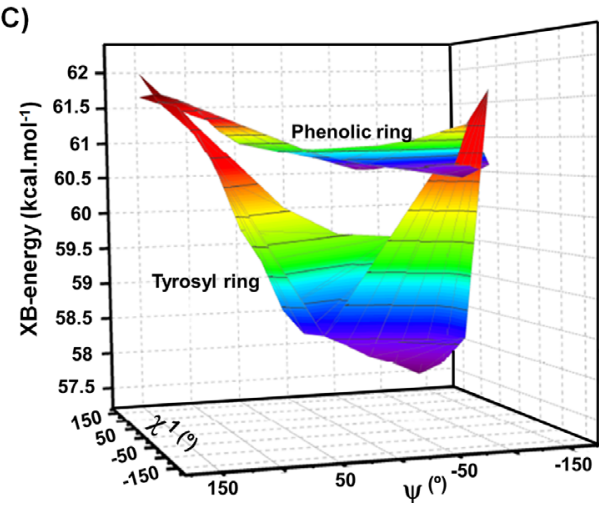

Figure 8. A) Conformational parameters of T4 and these parameters found in various protein.T4 complexes. Effects of B) $\Phi$ and $\Phi^{\prime}$, and C) $\chi^{1}$ and $\psi$ at $\Phi=0^{\circ}$ on the strength of XBs formed between 5- and 5'-iodo substituents of T4 and MeSe ${ }^{-[18]}$ Reproduced, with permission, from ref. [18]. Copyright: 2015, Wiley$\mathrm{VCH}$.

A)

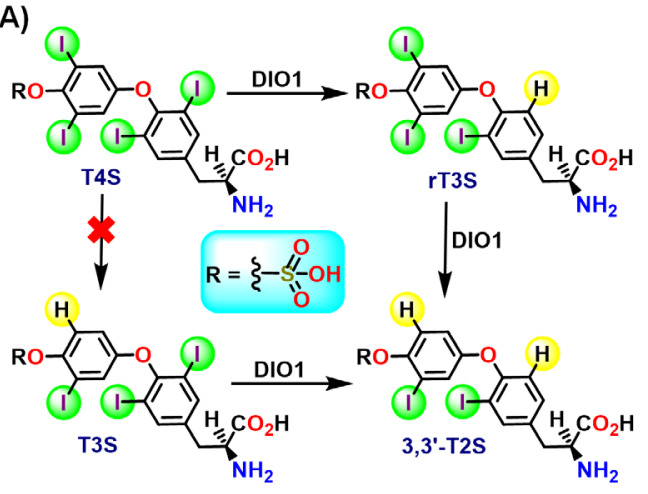

D)

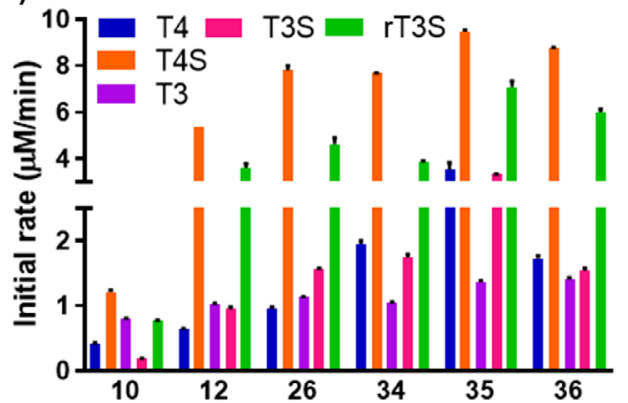

B)

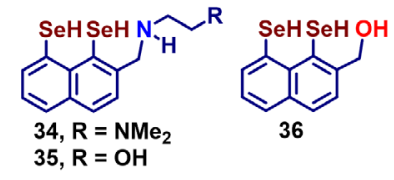

C)

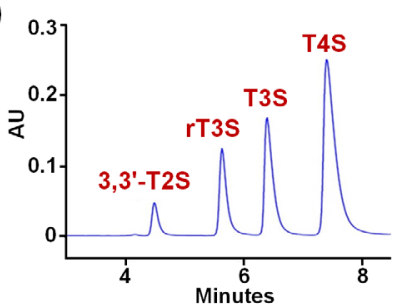

E)

\begin{tabular}{ccc}
\hline \multirow{2}{*}{ Compd } & \multicolumn{2}{c}{$\boldsymbol{E}_{\text {Se-.-1 }}$ (kcal/mol) } \\
\cline { 2 - 3 } & 5-iodine & 5'-iodine \\
\hline T4 & 4.18 & 3.83 \\
T4S & 4.98 & 5.19 \\
T3 & 3.96 & 3.03 \\
T3S & 4.95 & 4.43 \\
rT3 & 3.17 & 4.12 \\
rT3S & 4.36 & 5.25 \\
3,3'-T2 & 3.20 & 3.61 \\
3,3'-T2S & 4.23 & 4.44 \\
\hline
\end{tabular}

Figure 9. A) Deiodination of sulfated THs in the presence of DIO1. B) Chemical structures of 34-36. C) HPLC chromatogram showing deiodination of T4S in the presence of 12. D) Initial rates of deiodination of THs and sulfated metabolites in the presence of 10, 12, 26, and 34-36. E) Strengths of Se...I interactions formed by 5- and 5'-iodo substituents of THs and of their sulfated metabolites with MeSeH.

These results are consistent with the faster deiodination of sulfated metabolites than of THs in the presence of DIO1. Further- more, biomimetic $5^{\prime}$-deiodination of rT3S is significantly faster than 5-deiodination of T3S, thus indicating that $5^{\prime}$-deiodination 
contributes significantly to the overall deiodination of T4S. The higher activity of $\mathbf{3 6}$ in relation to $\mathbf{1 0}$ and $\mathbf{1 2}$ indicated that substituents other than amino groups in close proximity to one of the selenols can also enhance deiodination (Figure 9D). DFT calculations indicated that 5- and 5'-iodo substituents in the sulfated metabolites are engaged in stronger XBs with $\mathrm{MeSeH}$ than those in the parent THs (Figure 9E). Furthermore, the 5 '-iodo substituents of T4S and rT3S form stronger XBs with $\mathrm{MeSeH}$ than the 5-iodo substituents. These observations might account for the altered regioselectivity and faster biomimetic deiodination of sulfated metabolites in relation to $\mathrm{THs} .^{[20]}$

We also studied the deiodination of iodothyronamines (TAMs), which are generated endogenously by decarboxylation of $\beta$-alanine backbone of $\mathrm{TH} s$, in the presence of organoselenium compounds 12 and 36-41 (Figure 10A). Interestingly, of the nine metabolites, only 3-T1AM and TOAM (Figure 10A) have been detected in various organisms, and these metabolites induce hypothermia and bradycardia in mice. ${ }^{[1 a, 21]}$ Like THs, TAMs are sequentially deiodinated through the action of DIOs. ${ }^{[22]}$ T3AM and 3,5-T2AM undergo 5-deiodination to generate 3,3'-T2AM and 3-T1AM, respectively, in the presence of 12 and $36-41 .{ }^{[14,23]}$ As observed with $\mathrm{THs}$ and sulfated analogues, compounds 36-40, with different heteroatoms (oxygen, nitrogen, and sulfur) in close proximity to one of the selenols, exhibit higher activity than 12 (Figure 10B). Intramolecular Se...X $(X=N, O, S)$ interactions, responsible for higher activity of 3640, are observed in the ${ }^{77} \mathrm{Se}$ NMR spectra of these compounds and in the crystal structures of the corresponding diselenides (Figure $10 \mathrm{C}$ and D). Interestingly, compound 41, which might engage in intermolecular Se...S interactions, exhibits activity similar to that of $\mathbf{4 0}$, thus indicating that such intermolecular interaction might also enhance the deiodinase activity. ${ }^{[1,23]}$ Notably, T3AM and 3,5-T2AM undergo slower deiodination than T3 and 3,5-T2 in the presence of deiodinase mimics (Figure $10 \mathrm{~B}$ ), consistently with the observed rates of deiodination of TAMs through the action of DIOs. Interestingly, T3AM and 3,5-T2AM form weaker XBs with MeSe $\mathrm{C}^{-}$than T3 and 3,5-T2, respectively (Figure 10E). Detailed kinetic studies indicated that T3 and T3AM exist as a dimer and as the monomer, respectively, in solution and that the dimerization of T3 significantly enhances the collision frequency of the reactants and decreases the activation energy barrier. Furthermore, formation of $|. .$. $\mathrm{XBs}$, as observed in the crystal packing of T3 (Figure 10F), in the T3 dimer might also enhance the deiodination. NBO calculations indicate that one of the iodine atoms $\left(I_{A}\right)$ acquires more
A)

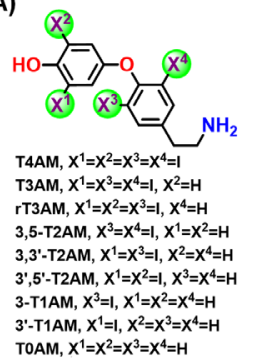

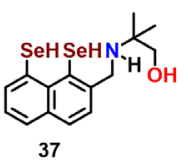
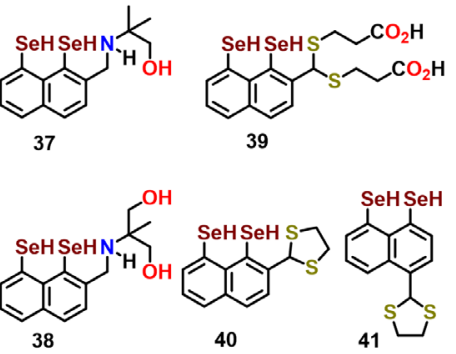

38
B)

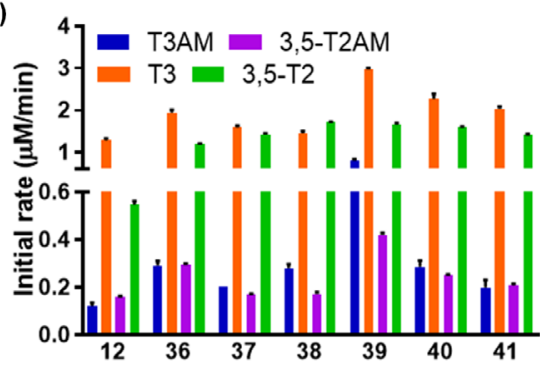

\section{C)}

Carbon Nitrogen Selenium Hydrogen Oxygen Sulfur

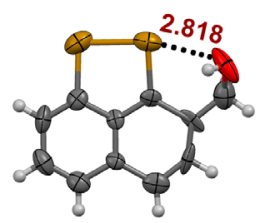

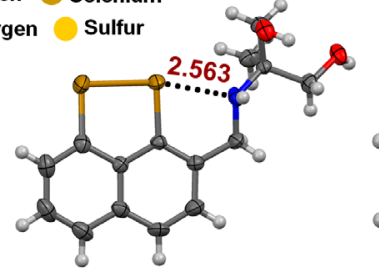

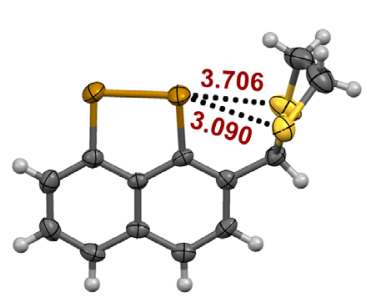

D)

\begin{tabular}{cc}
\hline Compd & $\delta(\mathrm{ppm})$ \\
\hline 36 & 52,211 \\
37 & $86,91,217$ \\
$\mathbf{3 8}$ & 91,212 \\
39 & 73,198 \\
$\mathbf{4 0}$ & 102,205 \\
$\mathbf{4 1}$ & 96,199 \\
\hline
\end{tabular}

E)
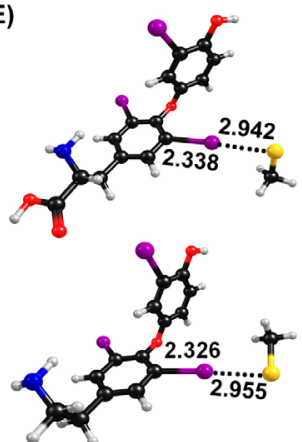

F)

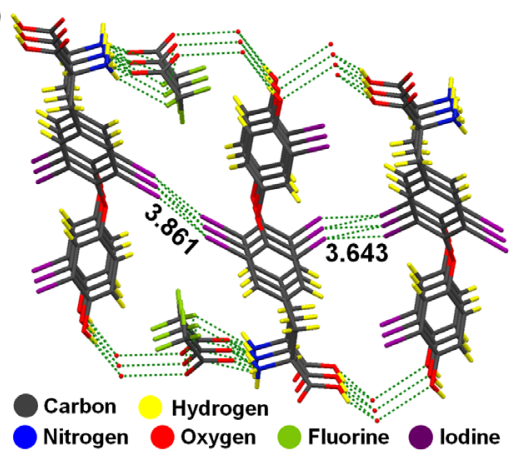

G)

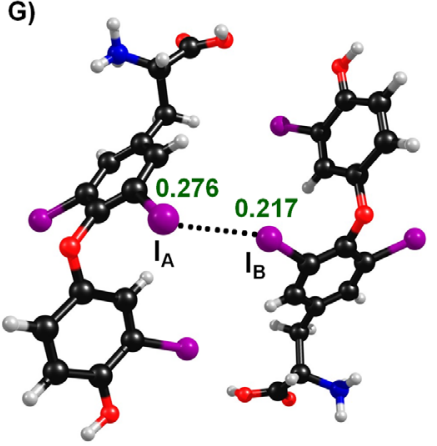

Figure 10. A) Chemical structures of TAMs and of 37-41. B) Initial rates of deiodinations of TAMs and THs in the presence of 12 and 36-41. C) Crystal structures of the corresponding diselenides of 36, 38, and 40. D) ${ }^{77}$ Se NMR signals of 36-41. E) Optimized geometries of halogen-bonded complexes formed through the 5-iodo substituents of T3 (top) and T3AM (bottom) with MeSe ${ }^{-}$. F) Crystal packing of T3, indicating the |...| interactions. G) |...| halogen-bonded dimer of T3, indicating the charges on iodo substituents. $\mathrm{C}-\mathrm{I}, \mathrm{Se} \cdots \mathrm{I} / \mathrm{O} / \mathrm{N} / \mathrm{S}$, and $|\cdots| \mathrm{l}$ distances are given in $\AA$. 
A)

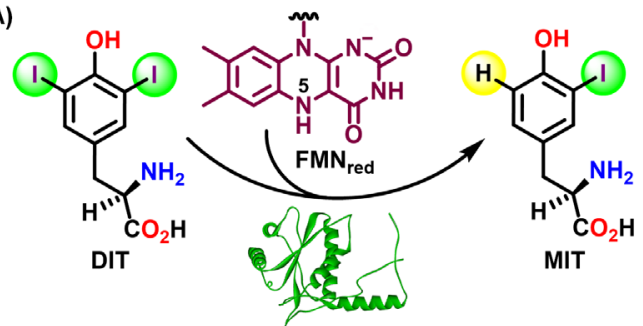

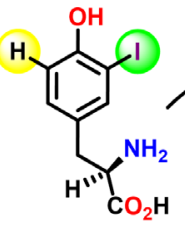

MIT

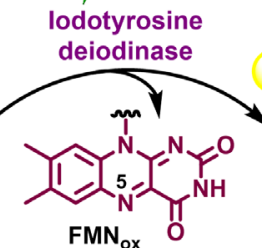

$\mathrm{FMN}_{\mathrm{Ox}}$<smiles>N[C@@H](Cc1ccc(O)c(I)c1)C(=O)O</smiles>

Tyr
B)

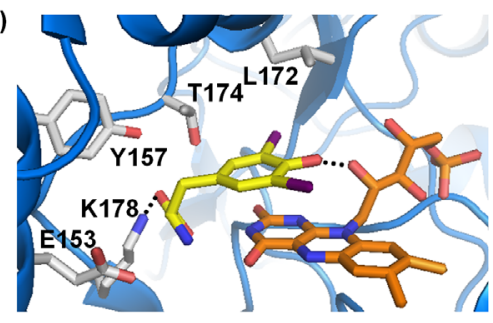

C)

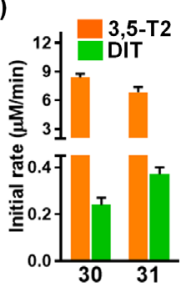

D)

\begin{tabular}{|c|c|c|}
\hline Compd & $\begin{array}{c}E_{\mathrm{se} \cdots \cdots} \\
\text { (kcall } \\
\text { mol) }\end{array}$ & $\begin{array}{c}E_{\mathrm{Te} \cdot \cdots \mathrm{l}} \\
(\mathrm{kcal} / \\
\mathrm{mol} /\end{array}$ \\
\hline $3,5-\mathrm{T2}$ & 3.50 & 4.31 \\
\hline 3-T1 & 2.62 & 3.39 \\
\hline DIT & 2.60 & 3.37 \\
\hline MIT & 2.15 & 2.78 \\
\hline
\end{tabular}

Figure 11. A) Deiodination of DIT and MIT through the action of iodotyrosine deiodinase (IYD). B) Crystal structure of IYD in complex with DIT and FMN (PDB

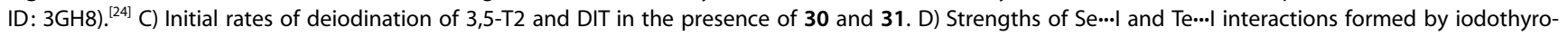
nines and iodotyrosines with $\mathrm{MeSeH}$ and $\mathrm{MeTeH}$.

positive charge $(0.276)$ in the $|. .$.$| halogen-bonded state than in$ the isolated state $(0.260)$, thus suggesting that $I_{A}$ in the T3 dimer would likely be engaged in a stronger Se...। interaction (Figure 10G). ${ }^{[14]}$

Acidic cleavage of the diaryl ether bond in T4 produces 3,5diiodotyrosine (DIT). DIT, together with MIT, is also produced during the biosynthesis of T4, through proteolysis of Tg. DIT and MIT are deiodinated through the action of iodotyrosine deiodinase (IYD) to produce MIT and L-tyrosine, respectively, and the released iodide is reused in the T4 biosynthesis pathway (Figure $11 \mathrm{~A}) .{ }^{[1 \mathrm{a}]}$ IYD uses flavin mononucleotide (FMN) as a cofactor; the reduced form of FMN $\left(\mathrm{FMN}_{\text {red }}\right)$ donates two electrons, facilitated by the direct positioning of the $\mathrm{C}-\mathrm{I}$ bond over the $\mathrm{N}-5 / \mathrm{C}-4$ a region of flavin (Figure $11 \mathrm{~B}$ ), and one proton to the iodinated substrates to generate the oxidized form of FMN

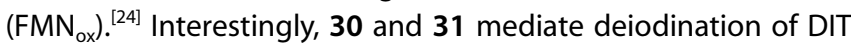
to MIT, but MIT does not undergo deiodination in the presence of these compounds. ${ }^{[16]}$ Furthermore, DIT does not undergo deiodination in the presence of $\mathbf{1 2}, \mathbf{3 2}$, and $\mathbf{3 3}$, which, in contrast, deiodinate 3,5-T2 (Figure 7C), thus indicating the importance of the extra phenolic group in 3,5-T2 for deiodination. Notably, the deiodination of 3,5-T2 in the presence of $\mathbf{3 0}$ and 31 is faster than that of DIT (Figure 11D). DFT calculations with $\mathrm{MeSeH}$ and $\mathrm{MeTeH}$ indicated that the strengths of Se/Te...I interactions depend on the number of iodo substituents and aryl rings (Figure 11D). Whereas tellurium forms stronger XBs than selenium in the cases both of iodotyrosine and of iodothyronine, iodotyrosine derivatives form weaker XBs than iodothyronine derivatives, thus accounting for the observed reactivity of these metabolites. ${ }^{[16]}$

\section{Dehalogenation of Halogenated Nucleo- bases and Nucleosides}

Purine and pyrimidine nucleosides are halogenated through the action of haloperoxidases. The halogenated nucleosides, such as iodinated and brominated uridine and cytidine deriva- tives (Figure 12A), are incorporated into the DNA of dividing cells during DNA replication, replacing thymidine (T). Under UV irradiation, the halogenated nucleosides can cause DNA damage, including single strand breaks and intra- and interstrand crosslinks, thus suggesting that dehalogenation of these nucleosides is essential. ${ }^{[25]}$ Therefore, motivated by the deiodination of THs and their metabolites in the presence of organochalcogen compounds, we studied the dehalogenation of the halogenated nucleobases and nucleosides shown in Figure $12 \mathrm{~A}$ in the presence of $\mathbf{1 0 - 1 2 , 2 6 , 3 6}$, and $42-44 .{ }^{[26]} \mathrm{Al}-$ though all of these compounds converted the halogenated uridine/2'-deoxyuridine/uracil and cytidine/2'-deoxycytidine/cytosine derivatives into the corresponding dehalogenated products, debromination was found to be significantly slower than deiodination for both types of nucleosides and nucleobases (Figure 12B). Electrostatic potential maps of 5-iodouracil (IU) and 5-bromouracil (BrU) showed that IU contains more positive charge on the $\sigma$-hole than BrU (Figure 12C), thus suggesting that IU can engage in stronger $\mathrm{XB}$ than $\mathrm{BrU}$ with organochalcogen compounds. The crystal structure of a complex between IU and $\mathbf{4 5}$ exhibited the potential of IU to engage in a Se...I XB in the presence of organoselenium compounds (Figure 12D). Detailed kinetic and mechanistic studies suggested that the deiodination follows a halogen-bond-mediated pathway as shown for THs, whereas debromination occurs through an addition/elimination pathway (Figure 12E). Notably, when using ${ }^{77}$ Se NMR spectroscopy, we detected an intermediate-compound 46-on performing the debromination of $\mathrm{BrU}$ in the presence of $\mathbf{1 0}$ at low temperature. ${ }^{[26]}$ These results indicate that selenium might play a broader role, beyond TH deiodination, in the metabolism of halogenated organics in the body.

\section{Summary and Outlook}

lodothyronine deiodinases (DIOs) are important in the activation and deactivation of thyroid hormones (THs). These enzymes catalyze the regioselective deiodination of thyroxine 
A)<smiles>[R]n1cc(O)c(=O)[nH]c1=O</smiles>

IU, $R=H, X=$

$\mathrm{BrU}, \mathrm{R}=\mathrm{H}, \mathrm{X}=\mathrm{Br}$

IdUd, $R=$ dRib, $X=$ I BrdUd, $R=d R i b, X=B r$ IUd, $R=R i b, X=I$<smiles>[R]c1cn([R])c(=O)nc1N</smiles>

IC, $R=H, X=$ I $\mathrm{BrC}, \mathrm{R}=\mathrm{H}, \mathrm{X}=\mathrm{Br}$ IdCd, $R=d R i b, X=1$ BrdCd, $R=d R i b, X=$ ICd, $R=R i b, X=I$ $\mathrm{BrCd}, \mathrm{R}=\mathrm{Rib}, \mathrm{X}=\mathrm{Br}$<smiles>[2H]c1cn([2H])c(=O)[nH]c1=O</smiles>
' $U, R=H$ dUd, $R=d R i b$ Ud, $R=$ Rib<smiles>[R]n1cc([2H])c(N)nc1=O</smiles>

$C, R=H$ $\mathrm{dCd}, \mathrm{R}=\mathrm{dRib}$ Cd, $R=$ Rib

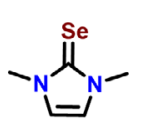

45

B)
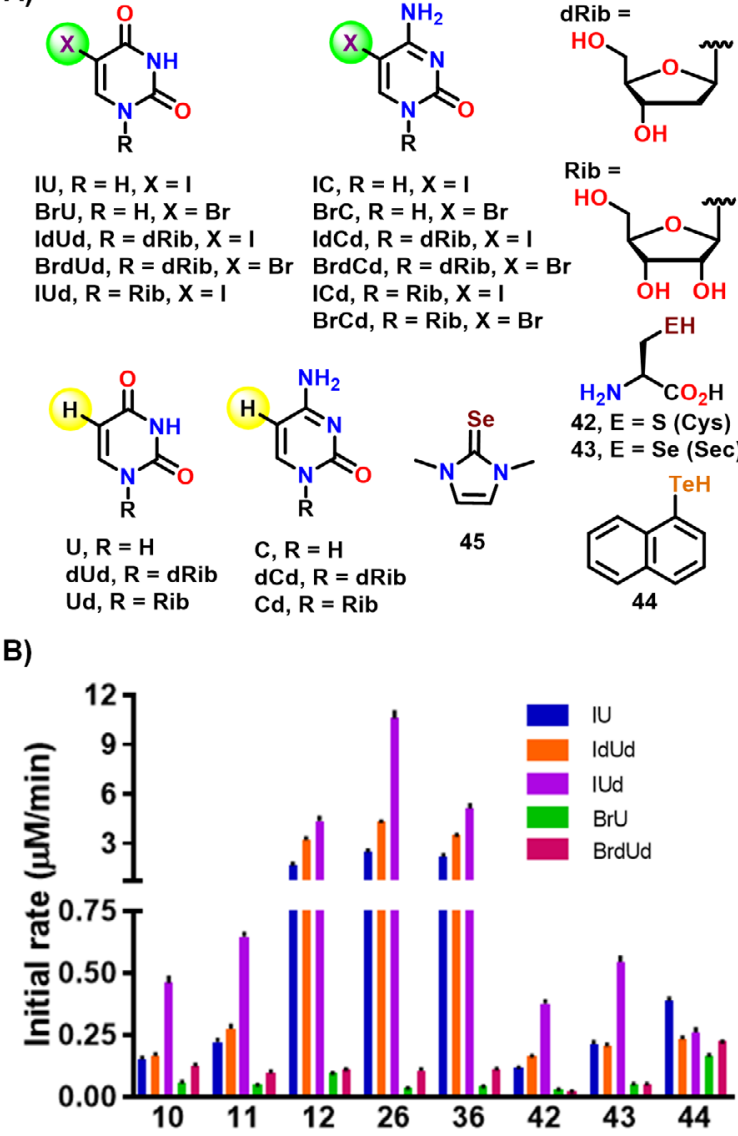

Rib $=$

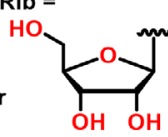

${ }_{\mathrm{H}_{2} \mathrm{~N}}^{\mathrm{EH}}$

$43, \mathrm{E}=\mathrm{Se}$ (Sec)

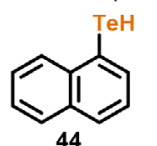

C)

$42, \mathrm{E}=\mathrm{S}$ (Cys)

\section{(a)}

0.05

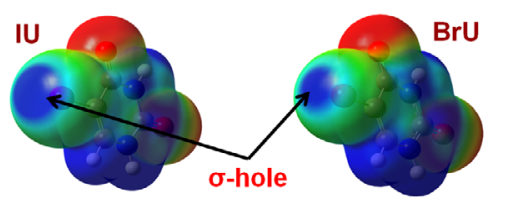

D)

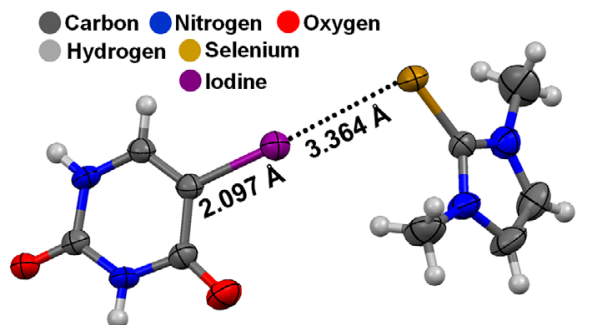

E)

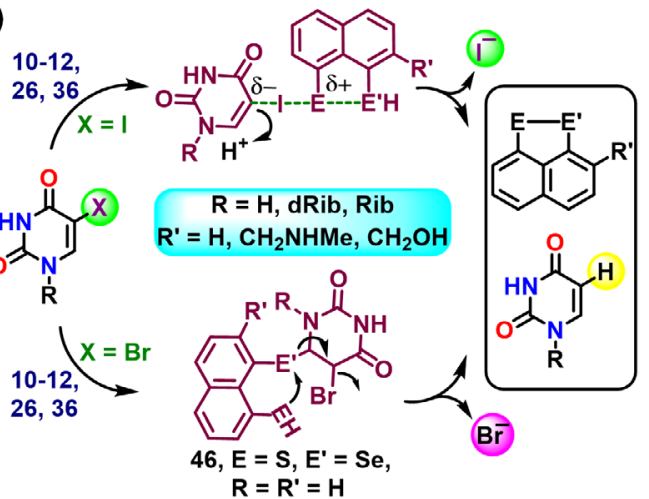

Figure 12. A) Chemical structures of halogenated nucleosides, nucleobases, and their dehalogenated analogues, together with those of $\mathbf{4 2 - 4 5 . ~ B ) ~ I n i t i a l ~ r a t e s ~}$ of dehalogenation of halogenated uracil, uridine, and 2'-deoxyuridine derivatives in the presence of 10-12, 26, 36, or 42-45. C) Electrostatic potential maps of IU and BrU, indicating the $\sigma$-hole. D) Crystal structure of the halogen-bonded complex between IU and 45. E) Proposed mechanism of dehalogenation. ${ }^{[26]}$

(T4) and its metabolites, and so are crucial for the maintenance of TH homeostasis. The type 1 and 2 isoforms (DIO1 and DIO2) mediate the 5 -deiodination of $\mathrm{T} 4$, which represents an activation pathway that produces the biologically active hormone T3. On the other hand, the type 3 enzyme (DIO3) catalyzes the removal of iodine from the inner ring (5-deiodination) of T4 to produce the biologically inactive rT3. However, the exact molecular mechanisms of deiodination through the action of the three isoforms of deiodinases remain unknown. It is not clear how the enzymes mediate the removal of one iodine atom selectively when four iodine atoms are present in T4. In this review we describe the development of organochalcogen ( $S$, $\mathrm{Se}$, and $\mathrm{Te}$ ) compounds as functional mimics of the deiodinases. Whereas naphthalene-based selenium/sulfur-containing compounds mediate the regioselective 5-deiodination of $\mathrm{THs}$ and iodothyronamines (TAMs), tellurium substitution in these compounds leads to both 5- and 5'-deiodination of THs. Furthermore, the sulfated TH metabolites also undergo 5- and 5'deiodination in the presence of the organoselenium compounds. On the basis of experimental and theoretical investigations, we have proposed a mechanism for the deiodination, involving cooperative $\mathrm{S} / \mathrm{Se} \ldots$... halogen-bonding and $\mathrm{S} / \mathrm{Se} \ldots \mathrm{S} / \mathrm{Se}$ chalcogen-bonding interactions. Our studies indicate that DIOs might also use Se...l halogen bonding for polarizing $\mathrm{C}-\mathrm{I}$ bonds and reductive deiodination of THs. However, the origin of the regioselectivity of deiodination of $\mathrm{THs}$ through the action of the DIOs is not clear. Although it has been reported that the binding between T4 and DIOs in different conformations can alter the reactivity of 5- and 5'-iodo substituents, further studies such as X-ray crystal structures of DIO enzymes bound to T4 and its derivatives are required in order to provide full understanding of the effects of conformational change on the regioselectivity of deiodination. Furthermore, studies on the regioselective deiodination of $\mathrm{TH}$ in the presence of organosulfur and selenium compounds in mammalian cells should be important for understanding of the cellular activity of the synthetic compounds. The physiological co-substrate for the deiodinases remains unknown, so model cellular studies might help in identifying suitable co-substrates for these deiodination reactions.

\section{Acknowledgements}

This study was financially supported by the Science and Engineering Research Board (SERB), New Delhi, India. G.M. acknowledges the SERB for the award of a J. C. Bose National Fellowship (grant no. $S B / S 2 / J C B-067 / 2015)$. 


\section{Conflict of Interest}

The authors declare no conflict of interest.

Keywords: biosynthesis - deiodination - halogen bonds iodothyronine deiodinases - selenium · thyroid hormones

[1] a) S. Mondal, K. Raja, U. Schweizer, G. Mugesh, Angew. Chem. Int. Ed. 2016，55，7606-7630; Angew. Chem. 2016，128，7734-7759; b) R Mullur, Y. Y. Liu, G. A. Brent, Physiol. Rev. 2014, 94, 355-382.

[2] a) I. Petitpas, C. E. Petersen, C. E. Ha, A. A. Bhattacharya, P. A. Zunszain, J. Ghuman, N. V. Bhagavan, S. Curry, Proc. Natl. Acad. Sci. USA 2003, 100 6440-6445; b) A. Wojtczak, V. Cody, J. R. Luft, W. Pangborn, Acta Crystallogr. Sect. D Biol. Crystallogr. 1996, 52, 758-765; c) A. Zhou, Z. Wei, R. J. Read, R. W. Carrell, Proc. Natl. Acad. Sci. USA 2006, 103, $13321-$ 13326.

[3] a) A. C. Bianco, D. Salvatore, B. Gereben, M. J. Berry, P. R. Larsen, Endocr Rev. 2002, 23, 38-89; b) J. Köhrle, Methods Enzymol. 2002, 347, $125-$ 167; c) U. Schweizer, C. Steegborn, J. Mol. Endocrinol. 2015, 55, R37R52.

[4] U. Schweizer, C. Schlicker, D. Braun, J. Kohrle, C. Steegborn, Proc. Natl. Acad. Sci. USA 2014, 111, 10526-10531.

[5] C. Beck, S. B. Jensen, J. Reglinski, Bioorg. Med. Chem. Lett. 1994, 4, $1353-1356$.

[6] A. A. Vasil'ev, L. Engman, J. Org. Chem. 1998, 63, 3911-3917.

[7] K. Goto, D. Sonoda, K. Shimada, S. Sase, T. Kawashima, Angew. Chem. Int. Ed. 2010, 49, 545-547; Angew. Chem. 2010, 122, 555-557.

[8] D. Manna, G. Mugesh, Angew. Chem. Int. Ed. 2010, 49, 9246-9249; Angew. Chem. 2010, 122, 9432-9435.

[9] D. Manna, G. Mugesh, J. Am. Chem. Soc. 2011, 133, 9980-9983.

[10] a) D. Manna, G. Roy, G. Mugesh, Acc. Chem. Res. 2013, 46, 2706-2715; b) S. Mondal, G. Mugesh, Mol. Cell. Endocrinol. 2017, 458, $91-104$.

[11] D. Manna, G. Mugesh, J. Am. Chem. Soc. 2012, 134, 4269-4279.

[12] a) L. C. Gilday, S. W. Robinson, T. A. Barendt, M. J. Langton, B. R. Mullaney, P. D. Beer, Chem. Rev. 2015, 115, 7118-7195; b) P. Metrangolo, F. Meyer, T. Pilati, G. Resnati, G. Terraneo, Angew. Chem. Int. Ed. 2008, 47,
6114-6127; Angew. Chem. 2008, 120, 6206-6220; c) P. Metrangolo, H. Neukirch, T. Pilati, G. Resnati, Acc. Chem. Res. 2005, 38, 386-395; d) S. Mondal, G. Mugesh, Cryst. Growth Des. 2016, 16, 5896-5906.

[13] C. A. Bayse, E. R. Rafferty, Inorg. Chem. 2010, 49, 5365-5367.

[14] S. Mondal, G. Mugesh, Chem. Eur. J. 2014, 20, 11120-11128.

[15] M. Fortino, T. Marino, N. Russo, E. Sicilia, Chem. Eur. J. 2015, 21, $8554-$ 8560.

[16] K. Raja, G. Mugesh, Angew. Chem. Int. Ed. 2015, 54, 7674-7678; Angew. Chem. 2015, 127, 7784-7788.

[17] D. Cesario, M. Fortino, T. Marino, F. Nunzi, N. Russo, E. Sicilia, J. Comput. Chem. 2019, 40, 944-951.

[18] S. Mondal, G. Mugesh, Angew. Chem. Int. Ed. 2015, 54, 10833-10837; Angew. Chem. 2015, 127, $10983-10987$.

[19] a) J. A. Mol, T. J. Visser, Endocrinology 1985, 117, 8-12; b) T. J. Visser, J. A. Mol, M. H. Otten, Endocrinology 1983, 112, 1547-1549.

[20] D. Manna, S. Mondal, G. Mugesh, Chem. Eur. J. 2015, 21, 2409-2416.

[21] a) C. S. Hoefig, R. Zucchi, J. Kohrle, Thyroid 2016, 26, 1656-1673; b) S. Piehl, C. S. Hoefig, T. S. Scanlan, J. Kohrle, Endocr. Rev. 2011, 32, 64-80; c) T. S. Scanlan, K. L. Suchland, M. E. Hart, G. Chiellini, Y. Huang, P. J. Kruzich, S. Frascarelli, D. A. Crossley, J. R. Bunzow, S. Ronca-Testoni, E. T. Lin, D. Hatton, R. Zucchi, D. K. Grandy, Nat. Med. 2004, 10, 638-642.

[22] S. Piehl, T. Heberer, G. Balizs, T. S. Scanlan, R. Smits, B. Koksch, J. Kohrle, Endocrinology 2008, 149, 3037-3045.

[23] S. Mondal, G. Mugesh, Org. Biomol. Chem. 2016, 14, 9490-9500.

[24] S. R. Thomas, P. M. McTamney, J. M. Adler, N. Laronde-Leblanc, S. E. Rokita, J. Biol. Chem. 2009, 284, 19659-19667.

[25] a) H. G. Gratzner, Science 1982, 218, 474-475; b) J. Rak, L. Chomicz, J. Wiczk, K. Westphal, M. Zdrowowicz, P. Wityk, M. Zyndul, S. Makurat, L. Golon, J. Phys. Chem. B 2015, 119, 8227-8238; c) C. R. Wang, Q. B. Lu, J. Am. Chem. Soc. 2010, 132, 14710-14713.

[26] a) S. Mondal, D. Manna, G. Mugesh, Angew. Chem. Int. Ed. 2015, 54, 9298-9302; Angew. Chem. 2015, 127, 9430-9434; b) S. Mondal, G. Mugesh, Chem. Eur. J. 2019, 25, 1773-1780.

Manuscript received: October 10, 2019

Accepted manuscript online: November 26, 2019

Version of record online: $\mathbf{\square} \mathbf{m}, 0000$ 


\section{MINIREVIEWS}

S. Mondal, D. Manna, K. Raja, G. Mugesh*

IIP Halogen Bonding in Biomimetic Deiodination of Thyroid Hormones and their Metabolites and Dehalogenation of Halogenated Nucleosides

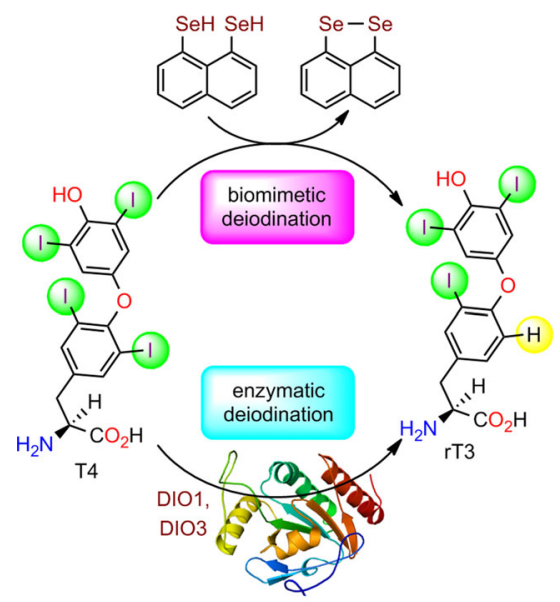

Selenoenzymes and thyroxine biosynthesis: Halogen bonding plays key roles in the regioselective deiodination of thyroid hormones and their metabolites. The formation of cooperative Se/S...I halogen bonds and Se/S...Se/S chalcogen bonds facilitates the heterolytic cleavage of $\mathrm{C}-\mathrm{I}$ bonds. 
